\title{
Vitamin D Supplementation for Patients with Chronic Kidney Disease: A Systematic Review and Meta-analyses of Trials Investigating the Response to Supplementation and an Overview of Guidelines
}

\author{
Marilena Christodoulou ${ }^{1}$ (D) . Terence J. Aspray ${ }^{2}$ (D) - Inez Schoenmakers ${ }^{1,3}$ (D)
}

Received: 10 November 2020 / Accepted: 22 March 2021 / Published online: 25 April 2021

(c) The Author(s) 2021

\begin{abstract}
A large proportion of patients with chronic kidney disease (CKD) are vitamin D deficient (plasma 25-hydroxyvitamin D $(25(\mathrm{OH}) \mathrm{D})<25$ or $30 \mathrm{nmol} / \mathrm{L}$ per UK and US population guidelines) and this contributes to the development of CKD-mineral bone disease (CKD-MBD). Gaps in the evidence-base for the management of vitamin D status in relation to CKD-MBD are hindering the formulation of comprehensive guidelines. We conducted a systemic review of 22 RCTs with different forms of vitamin D or analogues with CKD-MBD related outcomes and meta-analyses for parathyroid hormone (PTH). We provide a comprehensive overview of current guidelines for the management of vitamin D status for pre-dialysis CKD patients. Vitamin D supplementation had an inconsistent effect on PTH concentrations and meta-analysis showed non- significant reduction $(P=0.08)$ whereas calcifediol, calcitriol and paricalcitol consistently reduced PTH. An increase in Fibroblast Growth Factor 23 (FGF23) with analogue administration was found in all 3 studies reporting FGF23, but was unaltered in 4 studies with vitamin D or calcifediol. Few RCTS reported markers of bone metabolism and variations in the range of markers prevented direct comparisons. Guidelines for CKD stages G1-G3a follow general population recommendations. For the correction of deficiency general or CKD-specific patient guidelines provide recommendations. Calcitriol or analogues administration is restricted to stages G3b-G5 and depends on patient characteristics. In conclusion, the effect of vitamin D supplementation in CKD patients was inconsistent between studies. Calcifediol and analogues consistently suppressed PTH, but the increase in FGF23 with calcitriol analogues warrants caution.
\end{abstract}

Keywords Vitamin D supplementation · Vitamin D deficiency $\cdot$ Chronic kidney disease · Systematic review · Guidelines

\section{Introduction}

Chronic kidney disease (CKD) is an international public health problem affecting $5-10 \%$ of the world population [1]. It is defined on the basis of an estimated glomerular filtration rate (eGFR) and values less than $60 \mathrm{~mL} / \mathrm{min} / 1.73 \mathrm{~m}^{2}$ are considered the threshold for CKD [2-4]. Many are undiagnosed and asymptomatic. Only in the UK there are

Inez Schoenmakers

I.Schoenmakers@uea.ac.uk

Medical School, University of East Anglia, Norwich, UK

2 University of Newcastle Upon Tyne, Freeman Hospital, Bone Clinic, Newcastle, UK

3 Department of Medicine, Norwich Medical School, Faculty of Medicine and Health Sciences, University of East Anglia, Norwich Research Park, Norwich NR4 7TJ, UK approximately 1 million undiagnosed CKD patients [5]. CKD results in changes in vitamin D metabolism, calcium and phosphate homeostasis and bone metabolism $[6,7]$. This leads to CKD metabolic bone disease (CKD-MBD) [7] .

The prevalence of vitamin D deficiency is higher in CKD patients than in the general population [6]. Vitamin D status is most commonly assessed on the basis of the plasma concentration of 25-hydroxyvitamin D (25(OH)D or calcidiol). Vitamin D deficiency thresholds for population health are defined as $25(\mathrm{OH}) \mathrm{D}$ serum levels $<25$ or $30 \mathrm{nmol} / \mathrm{L}$ per UK and US guidelines $[8,9]$. Thresholds for patient management are mostly set higher.

Many factors contribute to the high prevalence of vitamin D deficiency in CKD patients. Dependent on the stage of CKD and presence or severity of secondary hyperparathyroidism (SHPT), supplementation with vitamin D, analogues or its active form is recommended. Guidelines for management of CKD patients combine those for the general 
population, general patient management and guidelines specific for CKD patients. This requires detailed knowledge of recommendations on vitamin $\mathrm{D}$ for the protection of population health, patient care and the specific guidelines to correct vitamin D deficiency. Due to differences in recommendations between advisory bodies, this is perceived to be confusing.

There are still many gaps in the evidence base for the management of vitamin D status in relation to CKD-MBD, including the role of vitamin $\mathrm{D}$ in the aetiology and management of SHPT, altered bone metabolism, bone density and integrity and fracture risk. These include the altered dose-response to vitamin D supplementation and the response in parathyroid hormone $(\mathrm{PTH})$ in these patients. The optimal concentration ranges of PTH and 25(OH)D for the management and prevention of CKD-MBD are also not well established for each stage of CKD.

Here we briefly summarise alterations in vitamin D metabolism and bone metabolism with CKD and gaps in the evidence base. We present the findings of a systematic review of recent RCTs with different forms of vitamin $D$ in CKD patients with a focus on CKD-MBD related outcomes. Meta-analyses were conducted to provide estimates of the effectiveness of supplementation on plasma PTH concentrations. Secondly, we provide a comprehensive review of the available guidelines for adult pre-dialysis renal patients for the management of vitamin D status and SHPT. We generated a road map, tabulating guidelines from different organizations on the form and dosages of vitamin D recommended to prevent or correct vitamin D deficiency and target values of plasma 25(OH)D concentrations, according to the different stages of CKD. Population guidelines are summarized as part of this road map where they apply to CKD patients.

\section{The Physiology of Altered Vitamin D and Bone Metabolism with CKD}

The alterations in vitamin D metabolism [6], calcium and phosphate homeostasis and bone metabolism [6] with CKD is multifactorial and associated with CKD-MBD [7].

A high proportion, $70-80 \%$, of CKD patients have a plasma 25(OH)D concentration below $50 \mathrm{nmol} / \mathrm{L} \mathrm{[6]} \mathrm{and}$ the majority well below the concentration recommended for patients with renal impairment ( $>75 \mathrm{nmol} / \mathrm{L}$ ), if not treated. Many factors contribute to the high prevalence of vitamin D deficiency in CKD patients and changes in vitamin D metabolism occur at several levels (Fig. 3).

Supply is decreased as a result of lower cutaneous vitamin $\mathrm{D}$ production due to skin hyperpigmentation, ageing, sun avoidance and dietary restrictions [10]. Losses are increased with proteinuria, when vitamin $\mathrm{D}$ binding protein and albumin and vitamin D metabolites bound to these proteins are lost in urine [10]. Hepatic conversion of vitamin D into $25(\mathrm{OH}) \mathrm{D}$ is reported to be suppressed in CKD patients [11-13]. Accordingly, the dose-response appears to be lower than in healthy individuals, although this is poorly characterized.

With the loss of functional renal tissue the capacity to convert $25(\mathrm{OH}) \mathrm{D}$ to $1,25(\mathrm{OH})_{2} \mathrm{D}(1,25$ dihydroxy vitamin $\mathrm{D}$ or calcitriol) is reduced leading to a decline in plasma $1,25(\mathrm{OH})_{2} \mathrm{D}$ [11]. Also the renal capacity to internalise $25(\mathrm{OH}) \mathrm{D}$ may be impacted, reducing its availability of $25(\mathrm{OH}) \mathrm{D}$. In healthy people, plasma $25(\mathrm{OH}) \mathrm{D}$ concentrations between 15 and $40 \mathrm{nmol} / \mathrm{L}$ are thought to be required to ensure there is no substrate limitation for renal $1,25(\mathrm{OH})_{2} \mathrm{D}$ production [14]. In people with CKD, higher concentrations may be required.

Plasma PTH increases in response to impaired $1,25(\mathrm{OH})_{2} \mathrm{D}$ production and calcium malabsorption in combination with increased resistance of the kidneys and bone to PTH, due to a downregulation of PTH receptor type 1 (PTHR1) [15]. An increase in plasma phosphate and Fibroblast Growth Factor-23 (FGF23) further stimulate PTH secretion.

The plasma concentration of FGF23 increases in early stages of CKD, before an increase in plasma phosphate is detectable [16]. FGF23 is a phosphaturic hormone which is predominantly produced by osteocytes and acts in the kidneys to increase phosphate excretion [16]. It requires the co-factor $\alpha$ KLOTHO, the expression of which decreases with ageing and renal impairment, thereby decreasing FGF23 receptor activation. FGF23 also has other functions. FGF23 stimulates the catabolism of both $25(\mathrm{OH}) \mathrm{D}$ and $1,25(\mathrm{OH})_{2} \mathrm{D}$. FGF23 also downregulates the expression of $1 \mathrm{a}(\mathrm{OH})$ ase, suppressing the production of renal $1,25(\mathrm{OH})_{2} \mathrm{D}$. Further, FGF23 can stimulate PTH secretion [16], although the mechanism of this FGF23-PTH interaction is not well understood. An increased plasma FGF23 concentration is associated with soft tissue calcification, increased risks of cardiovascular disease (CVD) and the promotion of CKD-MBD [16].

CKD-MBD has a heterogeneous phenotype due to the involvement of several underlying mechanisms, in which SHPT plays an important role [35]. CKD-MBD can either be characterised by an increase or a decrease in bone turnover, but may also be normal. An increase can lead to osteomalacia, which is characterized by the excessive presence of undermineralised bone tissue and osteoporosis defined as a low bone mineral density $(Z$-score $-2.5 \mathrm{SD})$ and loss of bone integrity. A decrease in bone remodelling leads to adynamic bone disease increasing fracture risk [1]. CKD-MBD is therefore generally characterized by a decrease of bone integrity, increased fracture risk and calcification of soft tissues [7] and alterations in bone turnover markers [1]. In the management of SHPT and 
CKD-MBD, maintenance of a sufficient vitamin D status is recognized as an important target.

\section{Clinical Trials of Vitamin D in CKD Patients and Gaps in the Evidence-Base}

There are gaps in the evidence base for the management of vitamin D status in relation to CKD-MBD, i.e. SHPT, altered bone metabolism, bone density and integrity and fracture risk. These include the dose- response to vitamin D supplementation and the response in PTH. The optimal concentration ranges of $\mathrm{PTH}$ and $25(\mathrm{OH}) \mathrm{D}$ for the management and prevention of CKD-MBD are not well established for each stage of CKD. This is reflected in the guidelines for the management of vitamin D status in CKD-MBD.

The limited number of randomized controlled trials reporting the effects of treatment with vitamin D or its analogues on CKD-MBD related outcomes provided conflicting results [18-31]. Several studies also reported the effect of supplementation on renal function and proteinuria [32] and markers of endothelial and cardiovascular function and inflammation [33, 34]. The effects were shown to depend on the stage of the disease $[35,36]$. Adverse treatment effects were reported, particularly with active vitamin D and analogues and includes hypercalcemia [37, 38], adynamic bone disease and increased FGF23 levels [39].

\section{Systematic Review and Meta-analyses of Randomised Controlled Trials}

In this systematic review we aimed to summarize the findings of the most recent randomized controlled trials reporting the effects of vitamin $\mathrm{D}$ or its analogues, conducted with pre-dialysis CKD patients and that report $25(\mathrm{OH}) \mathrm{D}, \mathrm{PTH}$, markers of calcium and phosphate and/or bone metabolism. Where provided, we also summarized adverse effects and other outcomes that may be relevant for vitamin D metabolism (e.g. proteinuria) or the effects of interventions on markers of vascular health. Findings are grouped according to form of vitamin $\mathrm{D}$ given, preceded by a short description of their characteristics. Meta-analyses were conducted to provide estimates of the effectiveness of supplementation on plasma PTH concentrations. There were insufficient studies and data to conduct meaningful meta-analyses for markers of bone turnover or FGF23.

\section{Methods}

\section{Search Strategy}

We searched for published studies indexed in MEDLINE, EBSCO, Science direct and PubMed from inception of 2003, the year that NKF KDOQI guidelines were published, to October of 2020. Search terms used: vitamin D, oral vitamin D, vitamin D supplementation, vitamin D analogues, paricalcitol, calcifediol, calciferol, ergocalciferol, chronic kidney/renal disease, renal/kidney impairment, impaired kidney/renal failure, RCT, randomised controlled trials. Search terms for outcomes were not used in order not to limit search results. Instead, papers were selected on basis of relevant outcomes. English was applied as a language limitation. Only full text published manuscripts were included. References were hand searched for additional publications.

\section{Inclusion Criteria}

The detailed process of study selection presented on Fig. 1. Only randomized controlled trials (RCT) were included that used any type of vitamin $\mathrm{D}$ in non-dialysis CKD patients ( $>18$ years old) and studies at any stage of the disease were considered. Studies were included if placebo controlled, compared 2 or more treatments or were randomized crossover studies. Studies had to include a definition of dosage and duration of the vitamin D administered and outcomes related to CKD-MBD. This systematic search provided 22 RCTs (Table 1).

\section{Quality Assessment}

The 22 studies were assessed for their methodological quality using the Van Tulder et al. criteria list [40] by two independent investigators (Table 1 ). High quality studies were defined with score $\geq 8$ and low quality with score $\leq 7.18$. Scores are provided in Table 1.

\section{Meta-analyses}

Plasma PTH concentrations were converted into uniform units $(\mathrm{pg} / \mathrm{ml})$. Random effect models were used for all metaanalyses because of differences in form, dosages, duration and study population. Heterogeneity was assessed with the $I^{2}$ test. Separate analyses were conducted for studies using the precursor of $1,25(\mathrm{OH})_{2} \mathrm{D}$ (i.e. vitamin $\mathrm{D}$ or $25(\mathrm{OH}) \mathrm{D}$ ) and those with $1,25(\mathrm{OH})_{2} \mathrm{D}$ or analogues. The decision to separate these studies was based on high heterogeneity $\left(\mathrm{Chi}^{2}\right.$ $P=0.001: I^{2}=65 \%$ ) resulting when both forms were analyzed together and on biological plausibility. Analyses used the reported mean and standard deviations or confidence intervals, either between treatment groups and/or placebo as appropriate. Not all studies reported sufficient detail for inclusion. Some studies could not be included because of the type of data reported (e.g. as \% difference between groups or geometric mean or median values for non-normally distributed data). In view of the limited number of placebo-controlled studies, baseline data were used as comparator for 
Fig. 1 Flow chart of systematic search and literature selection. Adjusted from PRISMA protocol 2019

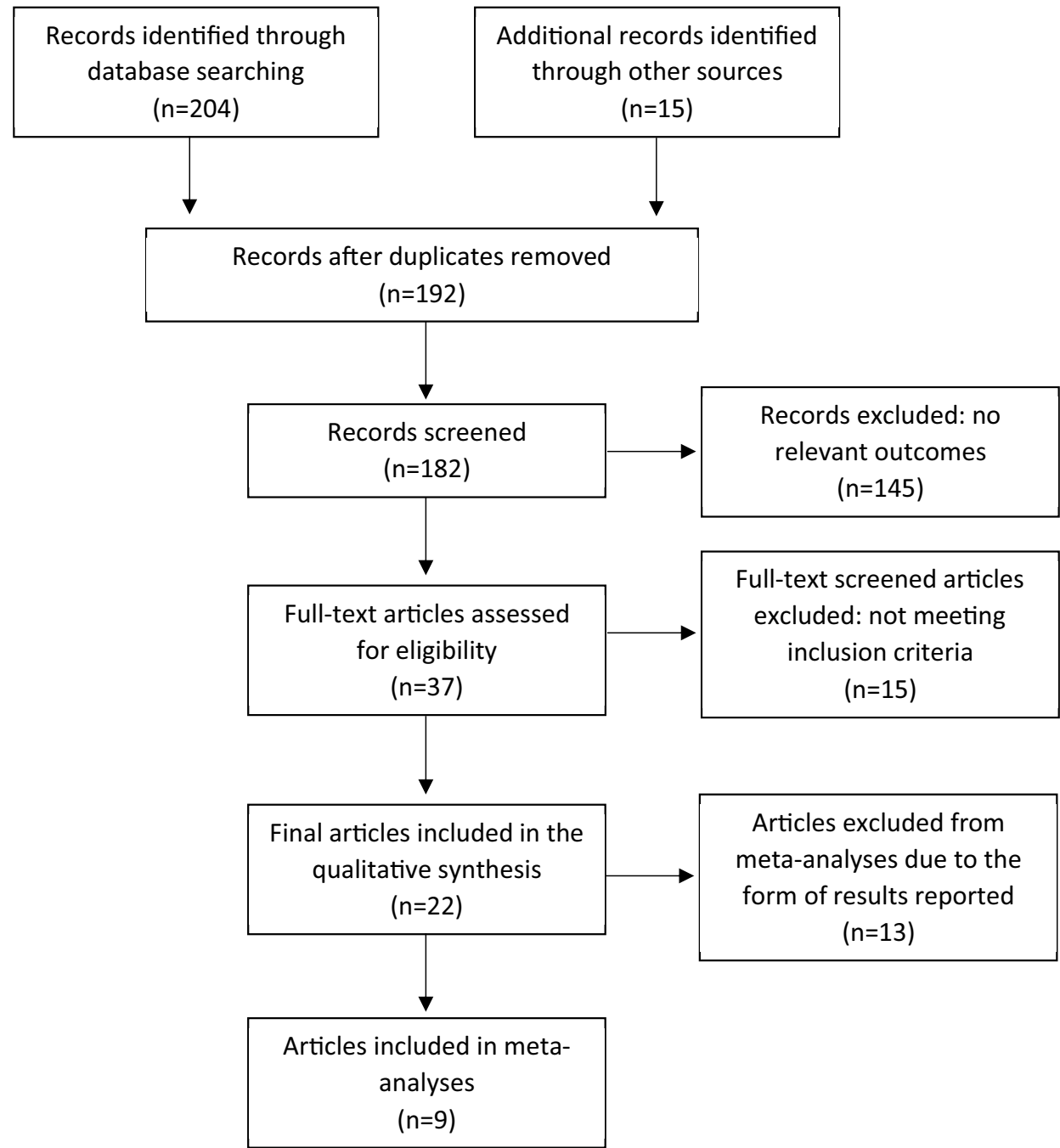

some studies. Four studies reported baseline and post-placebo treatment data and none of these individual studies reported a significant change in PTH and differences were small. This was confirmed by meta-analysis showing a nonsignificant change (results not shown).

Meta-analyses were performed using RevMan (version 5.4; non-Cochrane Collaboration). A $P$-value of $\leq 0.05$ was considered significant.

\section{Results}

\section{RCTs with Vitamin D Supplementation}

Vitamin $\mathrm{D}$ is the inactive precursor of $1,25(\mathrm{OH})_{2} \mathrm{D}$ and exists in two forms, vitamin $\mathrm{D}_{3}$ (cholecalciferol) and $\mathrm{D}_{2}$ (ergocalciferol). Vitamin D is the most commonly used form for the prevention and treatment of deficiency in both the general population and patient groups. Vitamin $\mathrm{D}_{3}$ supplementation leads to a somewhat longer sustained increase of $25(\mathrm{OH})$ $\mathrm{D}$, but otherwise the metabolism of $\mathrm{D}_{3}$ and $\mathrm{D}_{2}$ is identical.

Nine of the RCTs included in this systematic review used vitamin $\mathrm{D}_{3}$ (six studies) [25, 41-45] or $\mathrm{D}_{2}$ (three studies) [21, $29,46]$ supplementation (Table 2). All studies has a small sample size $(n<100)$. In some of these studies the group that received Vitamin D served as the reference group. They were all conducted with CKD patients stages 3-4. The doses varied from 2000 to 4000 IU daily or 40,000-50,000 IU weekly and the duration was between 1 and 12 months. All nine studies found a significant increase in plasma $25(\mathrm{OH}) \mathrm{D}$ concentrations. Four [41-43, 46] of these studies observed a significant reduction of $\mathrm{PTH}$, whilst in the remaining five, no significant change of PTH in response to the vitamin D supplementation was found [25, 29, 44, 45]. The small sample sizes, differences in dosages and duration of supplementation may explain these inconsistent results; higher doses show to be more effective in suppressing PTH. Only five of these studies provided sufficient detail for inclusion in meta-analysis, which showed a non-statistically significant 
decrease in PTH of $18 \mathrm{pg} / \mathrm{mL}$ (CI -37 to $2 ; P=0.8$ see Fig. 2a). When also two studies with calcifediol were considered, the effect on PTH was highly significant $(P<0.0001)$, but heterogeneity was substantial $\left(I^{2}=60 \%\right)$ (not shown).

Only three of the studies $[25,44,45]$ measured changes in $1,25(\mathrm{OH})_{2} \mathrm{D}$, with two showing a significant increase with supplementation. Most of the studies reporting no effect of the supplementation on PTH, also noted no effect on calcium and phosphate concentrations. Only one study measured FGF23 and found no change. Bone turnover markers were only reported in two studies. Alkaline Phosphatase (ALP), C-terminal telopeptide (CTx) and Tartrate-resistant acid phosphatase 5b (TRAP5b) were shown not to change with supplementation. One study reported a significant improvement on the endothelium dependent microcirculatory vasodilation and other markers of vascular function.

\section{RCTs with Calcifediol Supplementation}

In recent years, preparations of the 25 hydroxylated form of vitamin D, i.e. $25(\mathrm{OH}) \mathrm{D}$ or calcifediol were developed for oral administration. There are three forms; calcifediol and the extended release (ER) formula, provided as capsules and the immediate release (IR), provided as a liquid or capsule. The pharmacokinetic profile differs from the parent compound vitamin D. Intestinal absorption of $25(\mathrm{OH}) \mathrm{D}$ is known to be more efficient and is not dependent on fat absorption, the increase in plasma $25(\mathrm{OH}) \mathrm{D}$ is more rapid and the dose-response higher than that of the parent compound. The IR calcifediol formulation was approved in the USA in 1980 for treatment of CKD-MBD in dialysis patients [47]. However, it was withdrawn from the market in 2002, since it failed to show meaningful reduction of PTH ( $\geq 30 \%)$ in patients with CKD G3-4. IR calcifediol is still available in Europe and licensed for use in various conditions including vitamin D deficiency rickets, renal osteopathy and hypocalcaemia [47]. ER formulations of 25(OH)D are only available in the USA at the moment [47]. In 2016 ER calcifediol was approved in the USA to treat SHPT in adult CKD patients G3-4 and vitamin D insufficiency [47]. Studies in CKD patients showed that ER calcifediol results in a slower increase of $25(\mathrm{OH}) \mathrm{D}$ levels, more significant suppression of iPTH and less of an increase of 24,25(OH)D compared to IR-calcifediol [48].

Three ER calcifediol and one calcifediol study in CKD patients (G2-4) published since 2003 were found in our

Table 1 Quality assessment of the RCTs included in the systematic review according to Tulder et al. ${ }^{[40]}$

\begin{tabular}{|c|c|c|c|c|c|c|c|c|c|c|c|c|}
\hline Studies included & 1. & 2 & 3. & 4 & 5 & 6 & 7 & 8 & 9 & 10 & 11 & SCORF \\
\hline Dogan et al. 2008* & O & 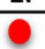 & e & O & O & 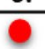 & O & 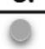 & 8 & 0 & 8 & 4 \\
\hline Oksa et al. 2008 & O & e & O & ( & O & e & C & O & C & 0 & O & 3 \\
\hline Moe et al. 2009* & C & C & O & O & 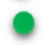 & ? & C & P & e & 0 & 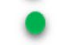 & 10 \\
\hline Petchey et al., 2013 & e & & O & O & 9 & P & 0 & O & ? & 0 & O & 9 \\
\hline Dreyer et al., 2014* & 8 & ? & $\mathrm{n} / \mathrm{a}$ & O & 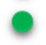 & 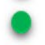 & O & P & & 0 & O & 10 \\
\hline Chandra et al. 2008 & 0 & ? & C & 8 & 9 & ? & 0 & C & 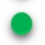 & 0 & O & 10 \\
\hline Westerberg et al. 2018* & & 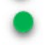 & 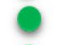 & O & 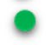 & 9 & 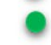 & P & 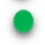 & 8 & O & 11 \\
\hline Sprague et al.,2014 & ○ & 9 & O & P & 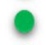 & O & 9 & C & O & 0 & P & 6 \\
\hline Petkovich et al. 2015 & ○ & 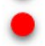 & $\mathrm{O}$ & O & O & O & - & O & 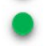 & 0 & O & 6 \\
\hline Sprague et al.2016 & 0 & O & O & 0 & 9 & C & 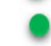 & C & C & O & C & 10 \\
\hline Coyne et al. 2006 & C & 0 & O & P & P & 9 & $\bullet$ & O & 9 & O & O & 9 \\
\hline de Zeeuw et al. 2010 & O & 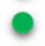 & ? & P & ? & O & ○ & C & O & ค & O & 9 \\
\hline de Boer et al., 2013 & O & 9 & & 8 & ? & 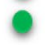 & $\mathrm{n} / \mathrm{a}$ & P & O & . & O & 9 \\
\hline Coyne et al. 2014 & ○ & ? & 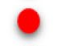 & O & O & O & - & P & P & 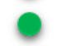 & O & 7 \\
\hline Larsen et al., 2013 & ? & 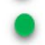 & & 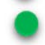 & 8 & O & ? & O & 8 & & C & 9 \\
\hline Lundwall et al., 2015* & P & 8 & O & & 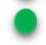 & O & 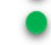 & 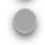 & O & & O & 9 \\
\hline Thadhani et al., 2012 & C & 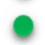 & O & C & C & C & - & O & O & 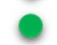 & O & 9 \\
\hline Riccio et al. 2015 & 0 & ? & O & O & O & O & - & 0 & O & O & C & 9 \\
\hline Zoccali et al. 2014 & 0 & e & O & O & O & O & ? & O & C & 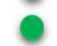 & O & 9 \\
\hline Susantitaphong et al., 2017* & 0 & ? & 8 & 0 & 0 & C & e & 0 & C & O & C & 8 \\
\hline Kovesdy et al. 2012* & 0 & 0 & 0 & 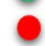 & 0 & 0 & 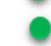 & 0 & 0 & & 0 & 6 \\
\hline Levin et al.2017* & 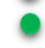 & 8 & 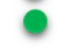 & & ? & 0 & e & O & 0 & & 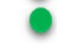 & 9 \\
\hline
\end{tabular}

Green: Yes, Red: No, Grey: Unknown. 1. Was the method of randomization adequate? 2. Was the treatment allocation concealed? 3. Were the groups similar at baseline regarding the most important prognostic indicators? 4. Was the patient blinded to the intervention? 5 . Was the care provider blinded to the intervention? 6. Was the outcome assessor blinded to the intervention? 7. Were co-interventions avoided or similar? 8. Was the compliance acceptable in all groups? 9. Was the drop-out rate described and acceptable? 10. Was the timing of the outcome assessment in all groups similar? 11. Did the analysis include an intention-to-treat analysis?

*Studies included in the meta-analyses 
systematic search [22, 48-50] (Table 1). Dosages and durations of treatment varied but a significant dose-dependent increase in $25(\mathrm{OH}) \mathrm{D}$ and a decrease in $\mathrm{PPTH}$ was seen after oral administration in all studies [22, 48, 49]. A meta-analysis was not conducted due to limited numbers of studies and reported data.

ER calcifediol showed a significant but gradual increase of serum $25(\mathrm{OH}) \mathrm{D}$ in all three of the studies in contrast to the sharp increase with intra-venous administration of calcifediol. Intra-venous administration did not significantly suppress iPTH but there was an increase in $24,25(\mathrm{OH})_{2} \mathrm{D}$ $(24,25$ dihydroxy vitamin $\mathrm{D})$, a catabolic product of $25(\mathrm{OH})$ D. ER calcifediol administration was associated with unaltered plasma calcium and phosphate concentrations in all studies and FGF23 concentrations in the 2 studies that included this measurement.

\section{RCTs: with Calcitriol and Vitamin D Analogues}

The active form of vitamin D and its analogues used in the treatment of CKD patients include calcitriol and the vitamin $\mathrm{D}$ analogues paricalcitol (19-nor-1,25(OH) $\left.{ }_{2} \mathrm{D}_{2}\right)$ and the $1,25(\mathrm{OH})_{2} \mathrm{D}$ precursor alfacalcidol $\left(1 \mathrm{a}(\mathrm{OH}) \mathrm{D}_{3}\right)$ [51]. $1,25(\mathrm{OH})_{2} \mathrm{D}_{3}$ is identical to the endogenous activated form of calcifediol $\left(25(\mathrm{OH}) \mathrm{D}_{3}\right)$. Paricalcitol and alfacalcidol, the latter of which requires hepatic hydroxylation at the 25 position, are synthetic analogues of vitamin D [51] and are also referred to as vitamin D receptor activators (VDRA). VDRAs have been used for the management of SHPT in CKD patients for a few decades [52] and show to have renoprotective properties such as reducing albuminuria, renal damage and dysfunction [27, 28, 53]. Paricalcitol suppresses PTH secretion whilst it has a lower stimulatory effect on intestinal absorption of calcium and phosphate compared to $1,25(\mathrm{OH})_{2} \mathrm{D}$ [28]. Paricalcitol is also associated with reduction of cardiovascular events [30], although sufficient studies with CKD patients are still lacking.

All twelve studies included CKD patients G3-4, however, there were differences between studies in patient characteristics. For example, diabetes, established SHPT, use of phosphate binders and proteinuria. The duration of administration varied from 2 to 48 weeks and the dosages used in these studies from 0.25 to $2 \mu \mathrm{g}$.

All twelve RCTs showed a significant reduction in plasma PTH after administration of paricalcitol or $1,25(\mathrm{OH})_{2} \mathrm{D}[19$, 26, 28, 30, 43, 46, 50, 53-58] (Table 1). This was also seen in a study that combined $1,25(\mathrm{OH})_{2} \mathrm{D}$ and Vitamin $\mathrm{D}_{2}$ [21]. Meta-analysis of the studies for which sufficient detail was available, confirmed this finding but heterogeneity was high (Fig. 2b). The effect of paricalcitol on serum 25(OH)D and $1,25(\mathrm{OH})_{2} \mathrm{D}$ concentrations were inconsistent. Two of the studies with paricalcitol $[26,55]$ reported a reduction of $1,25(\mathrm{OH})_{2} \mathrm{D}$ after supplementation.
Several studies compared different forms of supplementation. Kovesdy et al. compared the effects of vitamin $\mathrm{D}_{2}$ compared to paricalcitol in vitamin $\mathrm{D}$ deficient $\mathrm{CKD}$ patient with SHPT [46]. In both treatment groups, 25(OH)D significantly increased, but only in the paricalcitol group there was a significant decrease in PTH. Coyne's study compared the effects of $1,25(\mathrm{OH})_{2} \mathrm{D}$ with paricalcitol [58]. In both treatment group there was a significant decrease of PTH. However, paricalcitol appeared to be suppress PTH more compared to $1,25(\mathrm{OH})_{2} \mathrm{D}(-52 \%$ and $-46 \% \mathrm{PTH}$ reduction, respectively). Susantitaphong et al. examined the effect of Vitamin $\mathrm{D}_{2}$ with or without $1,25(\mathrm{OH})_{2} \mathrm{D}$ and found a suppression of PTH only in the combined group [21]. Levin et al. [50] compared the effects of oral calcifediol with $1,25(\mathrm{OH})_{2} \mathrm{D}$. Both treatment groups had a significant reduction of PTH, which was larger in the calcifediol group. A significant increase in $25(\mathrm{OH}) \mathrm{D}$ was shown in the calcifediol group, whilst there were no differences between the groups in the $1,25(\mathrm{OH})_{2} \mathrm{D}$ concentration. Meta-analysis comparing the effects of calcitriol or vitamin D analogues versus the administration of the precursor calcidiol or vitamin $\mathrm{D}$ on PTH, showed no significant difference between these forms. However, this analysis was limited to 4 studies for which sufficient detail was available and heterogeneity was high (Fig. 2c).

Inconsistent results were reported for serum/plasma calcium (four increase; six unchanged) and phosphate (two increase; eight unchanged) concentrations after calcitriol of analogue administration. Most of the studies reported no cases of hypercalcemia. Only one study reported significant higher incidence of hypercalcemia in the intervention group compared to placebo (22.6\% and $0.9 \%$, respectively) [30]. An increase in FGF23 after vitamin D analogues (paricalcitol) administration was found in all three studies reporting this outcome and in two of these studies, also a decrease in renal function was reported [26, 28, 55]. An increase in FGF23 was not reported in the four studies with Vitamin D or calcifediol and one with $1,25(\mathrm{OH})_{2} \mathrm{D}$. Meta-analysis of the FGF23 response to vitamin D or analogue administration was not conducted due to the low number of studies (3) and lack of sufficient information provided (e.g. not all manuscripts reported whether intact or c-terminal or intact FGF23 was measured).

All four studies that measured either alkaline phosphatase (ALP) or bone specific (BALP) after paricalcitol treatment reported a decrease in this marker of bone metabolism.

Further outcomes included markers of endothelial and cardiovascular function, insulin sensitivity and proteinuria and were inconsistent between studies. 


\section{Discussion of Clinical Trials of Vitamin D in CKD Patients}

As expected, 25(OH)D increased after supplementation, but the vitamin D-25(OH)D dose-response appeared to be lower than in healthy people. Individual participant data (IPD)level meta-analysis to characterize this relationship in CKD patients would be helpful to underpin the evidence base of vitamin D requirements to prevent and correct vitamin D deficiency in CKD patients.

The effect of vitamin D on PTH concentrations was inconsistent between individual studies and meta-analysis showed a non-significant suppressive effect. Comparing these studies with a meta-analysis of the PTH response in studies with participants not selected on the basis of their renal function [59, 60], results in CKD patients are less consistent. In these meta-analyses which included predominantly participants without renal impairement, a suppression of PTH was found in the majority of studies and meta-analyses found an overall reduction in PTH after vitamin D supplementation with generally lower dosages of vitamin D supplementation compared to dosages used in CKD patients. To address this, IPD-level meta-analysis of existing data and a vitamin D dose-ranging study in CKD patients with and without SHPT is urgently required to characterize the response of PTH to vitamin $\mathrm{D}$ treatment. This research would also facilitate the identification of patient groups that do and do not respond with a decrease in PTH to supplementation.

Administration of calcifediol was reported in four studies and all reported suppression of PTH. This may seem surprising since it requires renal activation to $1,25(\mathrm{OH})_{2} \mathrm{D}$. Although it is difficult to compare these results to the administration of vitamin $\mathrm{D}$, the use of calcifediol to suppress PTH in CKD patients holds promise since the risk of over suppression of PTH and hypercalcaemia appears less likely compared to calcitriol and paricalcitol.

We found that treatment with calcitriol and paricalcitol was associated a consistent and greater suppression of PTH. Increased risk of hypercalcaemia was only found in 1 of the 12 recent studies included in this review. IPD-level metaanalysis comparing calcifediol with vitamin D and calcifediol with calcitriol and its analogues may provide evidence of their relative effects. This may aid the incorporation of calcifediol in guidelines and provide alternative options for patients that might be prescribed calcitriol and paricalcitol.

An increase in FGF23 after treatment with vitamin D analogues was observed in all 3 studies reporting this outcome, but was unaltered in 4 studies with Vitamin D or calcifediol. This warrants further attention. FGF23 is a phosphaturic hormone, reducing phosphate reabsorption from the glomerular filtrate through downregulating the available sodium phosphate cotransporters [61]. FGF23 also downregulates the expression of $1 \mathrm{a}(\mathrm{OH})$ ase, suppressing the production of renal $1,25(\mathrm{OH})_{2} \mathrm{D}$ and upregulates $24(\mathrm{OH})$ lase increasing $1,25(\mathrm{OH})_{2} \mathrm{D}$ catabolism [61]. FGF23 is concentrationdependent and positively correlated with CKD progression, heart failure, vascular calcification, left ventricular hypertrophy and mortality in CKD patients [62]. These effects are partly thought to be caused by increased calcium retention caused by increased FGF23 and PTH concentrations [62], together with elevated aldosterone concentrations found in CKD patients due to activation of the Renin-Angiotensin-Aldosterone System (RAAS) [63]. High circulating aldosterone may enhance the effect of FGF23 on sodium retention in CKD patients and sodium and volume retention further contributes to the risk of vascular calcification [62]. An increase in both intact and c-terminal FGF23 with vitamin D supplementation is also reported in a meta-analyses of trials with deficient and healthy individuals [64], but so far not linked to increased risk of CVD events [64]. It was also earlier reported in CKD patients [39]. An increase in FGF23 may be an undesirable side effect of administration of vitamin D and its analogues and a better understanding of its effects with different forms of vitamin D is required, especially in CKD patients, in relation to their already increased FGF23 concentrations, alterations in vitamin D metabolism and increased risk of CVD.

Few RCTs reported the effect of vitamin D on markers of bone metabolism and variations in the range of markers prevented direct comparisons. However, all four studies that measured either ALP or BALP after paricalcitol treatment reported a decrease in this marker indicative of increased bone turnover in CKD patients.

Several factors may have influenced the overall findings. These include form, frequency and dosages of vitamin D and its analogues used. The selection of patient population, co-morbidities and their use of other medication will have influenced the response to supplementation. Further, the method used for estimating renal function may have influence the selection of study participants.

\section{Methods for Estimating Renal Function}

All studies included in this review used eGFR as a measure to assess kidney function. None applied a direct method. Most studies used creatinine based algorithms, and the majority the Modification of Diet in Renal Disease 4-variable (MDRD-4) equation, except Zoccali et al. [55] who used the Chronic Kidney Disease Epidemiology Collaboration (CKD-EPI) Creatinine-Cystatin $\mathrm{C}$ algorithm, that incorporates both creatinine and cystatin C. Plasma creatinine is significantly affected by age, nutrition, gender, physical activity and muscle mass [65, 66]. Also, Agarwal et al. showed that short-term paricalcitol treatment in 


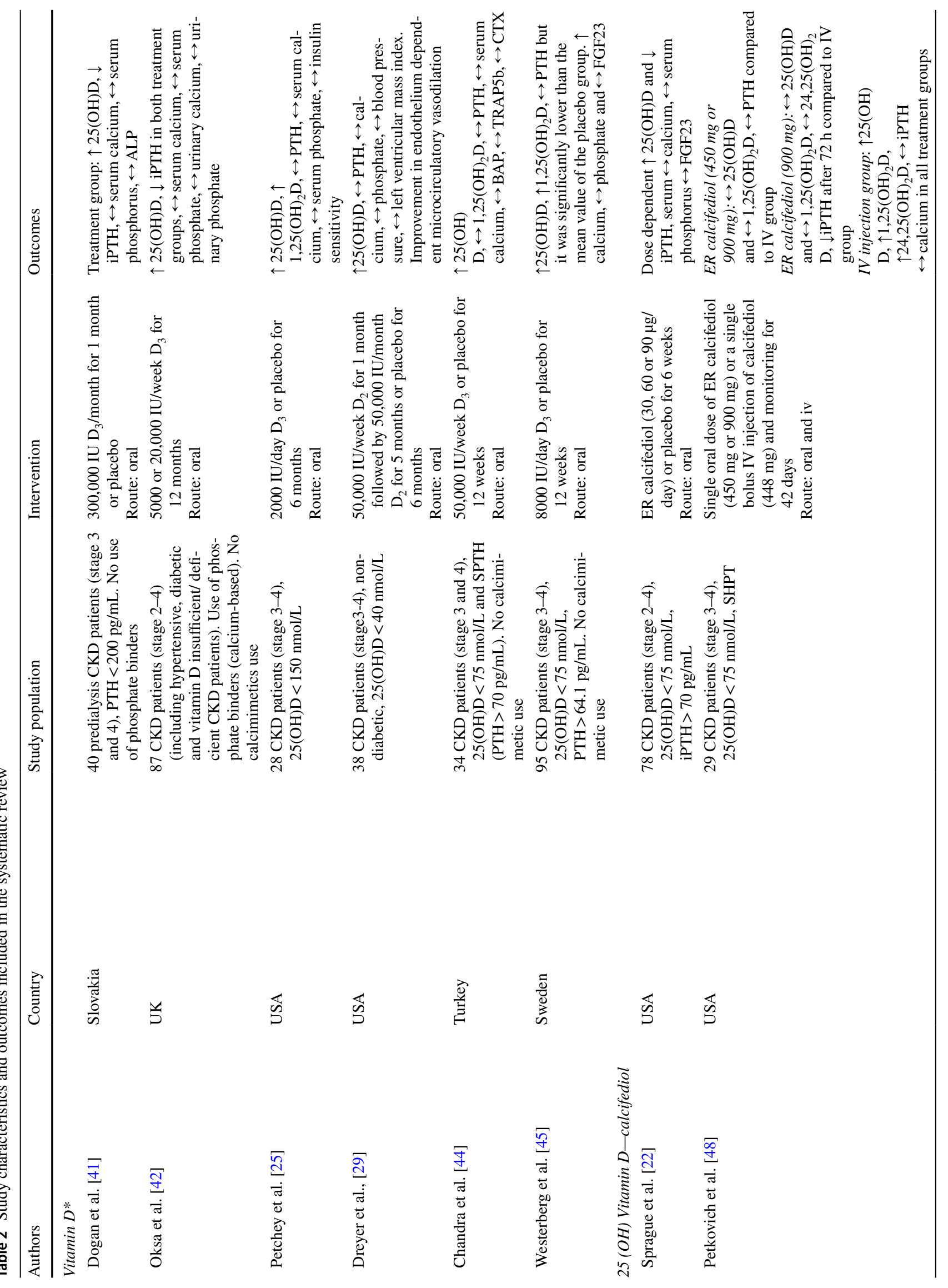




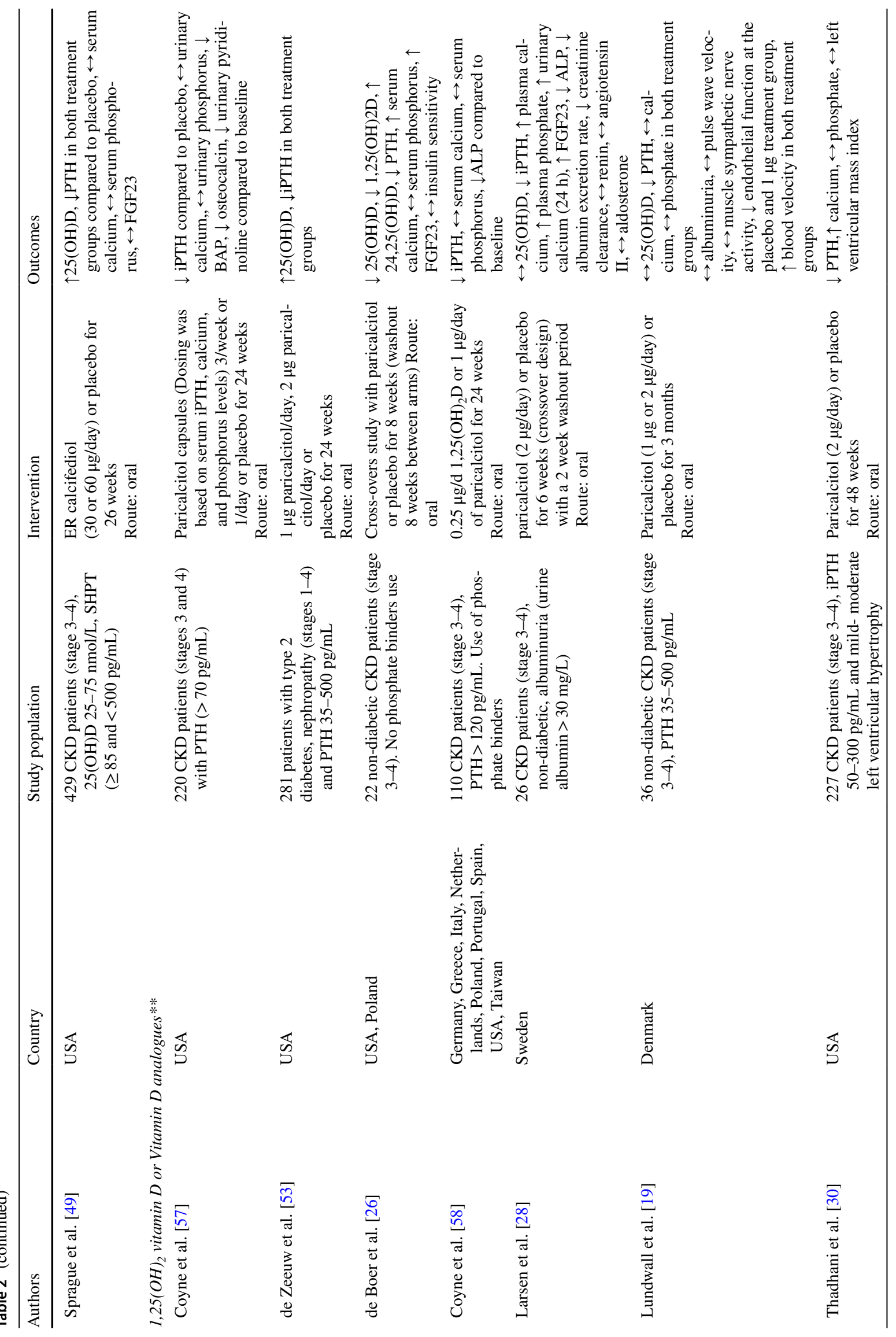




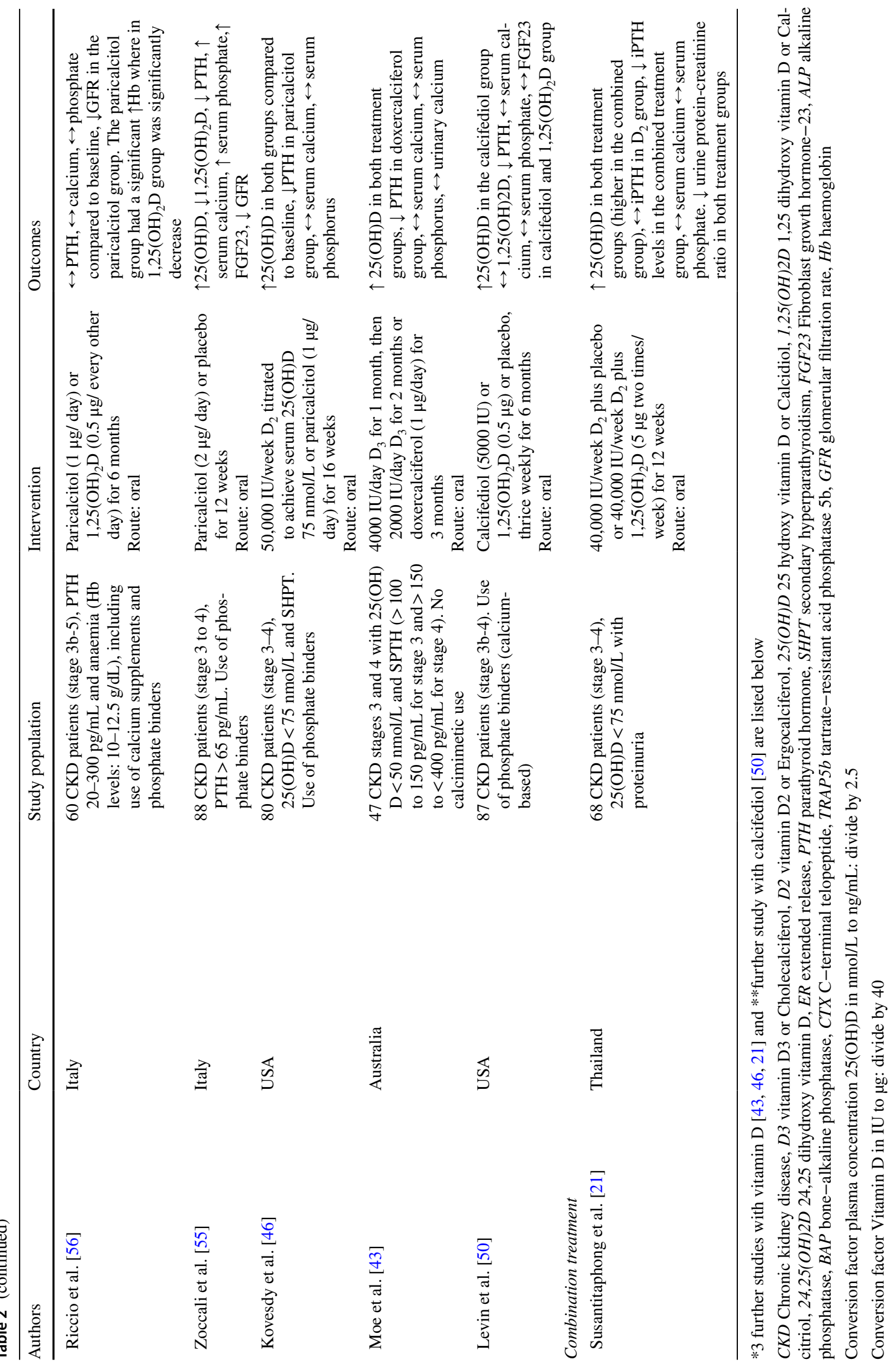


CKD patients can increase serum creatinine and creatinine excretion without altering creatinine clearance $[65,66]$. MDRD-4 is the most commonly used formula for eGFR in medical practice. However, there are differences between guidelines. The UK National Institute of Health and Care Excellence (NICE) recommends the use of CKD-EPI for the majority of patients [67], but for the assessment of eGFR in those with CKD stage $3 \mathrm{a}$ (eGFR $45-59 \mathrm{~mL} / \mathrm{min} / 1.73 \mathrm{~m}^{2}$ ) and no proteinuria, the use of cystatin $\mathrm{C}$-based equations is recommended [68]. Also the Kidney Disease Improving Global Outcomes (KDIGO), National Kidney foundation (NKF) and Caring for Australasians with Renal Impairment (CARI) guidelines recommend the use of CKD-EPI. The Cockroft-Gault algorithm may be the preferred option for the older population since this incorporates body size [69].

Cystatin $\mathrm{C}$ is a relatively new biomarker. Cystatin $\mathrm{C}$ based eGFR has been reported to correlate better with mortality risk factors in CKD patients than creatinine based eGFR [65, 66]. Cystatin $C$ is filtered by the glomerulus, is not secreted by the renal tubules and it is generated at a constant rate by all cells in the body $[65,66]$. There are two formulae based on cystatin C; the CKD-EPI using cystatin C and CKD-EPI using a combination of cystatin $C$ and creatinine $[65,66]$.

There are considerable differences in the resulting eGFR value and CKD classification [69] and accordingly, the choice of the method may have influenced the characteristics of patients included in studies.

\section{Medication Use and Vitamin D}

Many drugs used by CKD patients to manage symptoms of CKD and CVD influence vitamin D metabolism and synthesis, although the mechanisms are still largely unknown [70]. The most commonly used therapies for CKD patients involve angiotensin inhibitors (ACE), aldosterone receptor antagonists (ARAs) and receptor blockers [70]. They are used to inhibit the RAAS [71]. Statins are also frequently used [72]. There are conflicting results on the association between these medications and vitamin D status. Yuste et al. found significant lower 25(OH)D levels in patients treated with statins compared to the patients treated with ACE inhibitors or ARAs [70]. In the same study they found higher $25(\mathrm{OH})$ D levels in patient treated with xanthine oxidase inhibitors (medication for hyperuricemia) [70]. On the other hand, a different study showed no significant associations between concentrations of $25(\mathrm{OH}) \mathrm{D}$ and treatment with statins, ACE inhibitors and/or ARAs [73]. The use of these medications is however seldomly reported in RCTs.

Medication use or dietary strategies to manage hyperphosphatemia in CKD can also have influenced the findings and the reported side effects in these studies. Hyperphosphatemia is usually managed by dietary restriction of phosphate intake or prescription of phosphate binders [74] to decrease the availability of phosphate for intestinal absorption. There are three types of phosphate binders available: containing calcium, aluminum or non-calcium containing binders. Calcium based binders can be used as the initial binder therapy in CKD patients but are not the preferred option in case of hypercalcemia and/or when plasma PTH concentrations are $<150 \mathrm{pg} / \mathrm{mL}$ on two consecutive blood tests [75]. Calcimimetics are allosteric activators of the calcium sensing receptor of parathyroidal cells [51]. Calcimimetics are usually prescribed in CKD patients with SHPT to activate calcium receptors and thus suppressing PTH [51] and are used when vitamin $\mathrm{D}$ analogues have failed to reduce SHPT. Calcimimetics in combination with active vitamin D therapy are used to reduce the risk of developing hypercalcemia and hyperphosphatemia [76].

A secondary analysis of a large study showed that the choice of phosphate binders may significantly impact vitamin D metabolism and may influence the safety profile of vitamin D administration. In the Phosphate Normalization Trial on CKD patients [93], participants were randomized to receive either sevelamer carbonate, lanthanum carbonate, calcium acetate for 9 months after which vitamin D metabolites were measured. In the group taking calcium acetate, $24,25(\mathrm{OH})_{2} \mathrm{D}$, the vitamin $\mathrm{D}$ metabolite ratio (VMR) $\left[24,25(\mathrm{OH})_{2} \mathrm{D}: 25(\mathrm{OH}) \mathrm{D}\right]$ increased and $1,25(\mathrm{OH})_{2} \mathrm{D}$ decreased [77]. Also, the group taking sevelamer carbonate had an increased $24,25(\mathrm{OH})_{2} \mathrm{D}$ and $\mathrm{VMR}$, but this was lower than in the calcium acetate group [77]. No changes in $1,25(\mathrm{OH})_{2} \mathrm{D}$ were reported [77]. In the group taking lanthanum there we no changes in vitamin D metabolite concentrations.

In the studies included in this systematic review, patients were included that did or did not use phosphate binders and/ or calcimimetics. No clear pattern in the response or incidence of hypercalcemia appeared amongst these studies.

\section{Summary of Published Guidelines}

\section{Guidelines for Dietary Vitamin D Intakes and Supplementation for Population Health and Patient Management}

\section{General Population Requirements and Recommendations}

Population guidelines for dietary vitamin D intakes are partly based on the required intakes to prevent vitamin D deficiency or to achieve pre-defined target ranges of $25(\mathrm{OH})$ D or sufficiency. Also evidence from RCTs and other research designs linking vitamin $\mathrm{D}$ intake and status to health outcomes are considered. Thresholds for deficiency, i.e. the plasma concentration of $25(\mathrm{OH}) \mathrm{D}$ below which the 


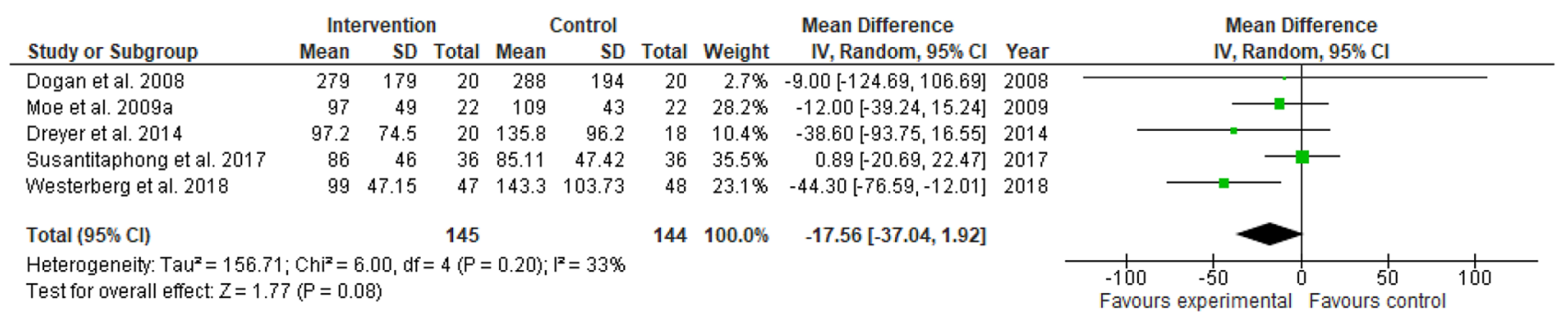

a Vitamin $D_{2}$ and $D_{3}$

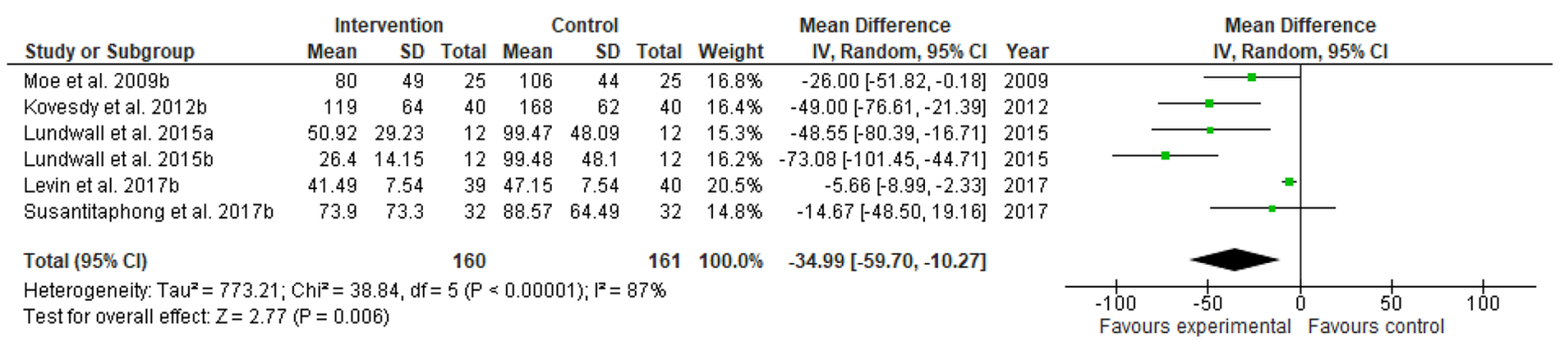

\section{b Active and analogues}

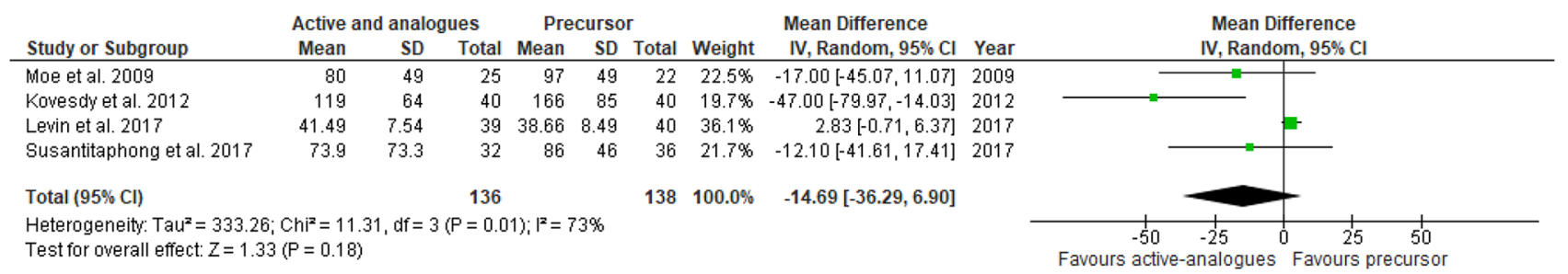

\section{c Active and analogues vs precursor}

Fig. 2 Forest plots of the effect of different forms of vitamin D supplementation on PTH concentrations in CKD patients. Top: a effect of vitamin $\mathrm{D}_{2}$ or $\mathrm{D}_{3}$ on PTH. Middle: $\mathbf{b}$ effect of calcitriol or ana-

risk of disease increases, are predominantly defined on the basis of skeletal health outcomes, but in some guidelines also other health outcomes are considered. In most guidelines, minimal contribution of vitamin D synthesis in the skin is assumed. There is considerable variation in the definition and thresholds or ranges of $25(\mathrm{OH}) \mathrm{D}$ concentration that encompasses vitamin D sufficiency or target ranges of 25(OH)D between health authorities. In addition, strategies (e.g. type of data considered) to set requirements differ between health authorities. Review of approaches are beyond the scope of this review and are provided in Bouillon 2017 [78]. logues on PTH. Bottom: $\mathbf{c}$ effect of calcitriol or analogues (active) versus Vitamin $\mathrm{D}_{2}$ or $\mathrm{D}_{3}$ (precursors) on PTH. PTH concentrations are given in $\mathrm{pg} / \mathrm{mL}$. Details on form and dosages are given in Table 1

Dietary reference values (DRV) or equivalents, defined by different public health institutes vary as a consequence of differences in the defined threshold for deficiency or target values for $25(\mathrm{OH}) \mathrm{D}$ and by age group or physiological state and are summarized in Table $3[8,79,80]$. The umbrella term DRV is used in Europe and World Health Organization/Food and Agriculture Organization (WHO/FAO) and similarly, dietary reference intake (DRI) in the US. These comprise a range of nutrient values that apply to the general population or specific population groups [8,79-81]. The DRV includes the Reference Nutrient Intake (RNI) which is the intake to meet the requirements of $97.5 \%$ of the population. There where this cannot be established, an Adequate 
Table 3 Population daily Reference Nutrient Intake (RNI) or Recommended Dietary Allowance (RDA) or equivalents for vitamin $\mathrm{D}$ according to different countries and organizations $\Psi$

\begin{tabular}{llll}
\hline Country/organization & Adults IU/d $(\mu \mathrm{g} / \mathrm{day})$ & $\begin{array}{l}\text { Older than 65 years } \\
\text { IU/d }(\mu \mathrm{g} / \mathrm{day})\end{array}$ & $\begin{array}{l}\text { Deficiency } \\
\text { of 25(OH)D } \\
{[78]}\end{array}$ \\
\hline Nordic countries [95] & & $400-800(10-20)$ & $25-30 \mathrm{nmol} / \mathrm{L}$ \\
UK [96] & $400(10)$ & $400(10)$ & $25 \mathrm{nmol} / \mathrm{L}$ \\
Ireland [97] & $400(10)$ & $400(10)$ & $30 \mathrm{nmol} / \mathrm{L}$ \\
Netherlands [98] & $0-400(0-10)$ & $800(20)$ & $25-30 \mathrm{nmol} / \mathrm{L}$ \\
Belgium [98] & $0-400(0-10)$ & $600(15)$ & \\
France [98] & $400-600(10-15)$ & $400-600(10-15)$ & \\
DACH [98] & $200(5)$ & $800(20)$ & $25-30 \mathrm{nmol} / \mathrm{L}$ \\
Spain [98] & $800(20)$ & $600(15)$ & $25-30 \mathrm{nmol} / \mathrm{L}$ \\
Australia and New Zealand [86] & $600(15)$ & $600-800(15-20)$ & $50 \mathrm{nmol} / \mathrm{L} *$ \\
EFSA 2017 [81] & $600(15)$ & $600(15)$ & $30 \mathrm{nmol} / \mathrm{L}$ \\
Institute of Medicine [82] & $600(15)$ & $800(20)$ & $25 \mathrm{nmol} / \mathrm{L}$ \\
WHO/FAO & $600(15)$ & $200(5)$ &
\end{tabular}

After Lips et al. [79] and Bouillon [78]

*Adequate intake set for vitamin D intake based on target value of $25(\mathrm{OH}) \mathrm{D} ; \Psi$ to convert from IU to $\mu \mathrm{g}$ divide by 40
Intake (AI) is defined. Similarly in the US, the recommended dietary allowance (RDA) represents the requirements of $97.5 \%$ of the population [82]. Population guidelines differ from clinical guidelines as the latter consider altered dietary requirements associated with underlying conditions.

Although vitamin D deficiency is one of the most common nutritional deficiencies in the world, no routine screening for the general population and most patient groups is recommended $[9,67,81,82]$. Only people at high risk or with clinical features of vitamin D deficiency are recommended to be tested [83]. For example, KDIGO working group and NKF recommend annual screening for vitamin $\mathrm{D}$ deficiency for CKD patients [84]. CKD patients are classified as a high risk group due to their dietary modification (restricted protein intake), advice to restrict sunlight exposure and reduced cutaneous synthesis associated with common CKD comorbidities and renal losses.

\section{Guidance for Patient Management and CKD Patients}

Clinical guidelines for patient management or for specific patient groups provide guidance for the prevention and correction of vitamin D deficiency. These are partly based on population guidance or define specific target values for $25(\mathrm{OH}) \mathrm{D}$ and vitamin $\mathrm{D}$ intakes, based on altered supply or bio-availability, metabolism and/or requirements. The UK NICE [67] and the US Endocrine Society [9] offer guidelines for prevention and treatment of vitamin D deficiency in patients, including CKD patients. The UK Royal Osteoporosis Society (ROS) [85] provides guidelines that focus on patients with osteoporosis and for osteomalacia and osteoporosis prevention (Table 4). Specific guidance for the management of CKD-MBD were developed by the NKF, the KDIGO CKD-MBD Guideline [84] and CARI [86-88]. Approaches and criteria used are discussed in more detail below.

The NKF and KDIGO guidelines cross-refer to guidelines for the general population, especially for patients in early stages of CKD. Specific guidelines for patients with advanced renal impairment include the use of vitamin D analogues [84]. These guidelines, including the daily recommended vitamin D intakes are detailed in Tables 5 and 6 by CKD category. Additional recommendations are in place for patients with CKD 3-4. For these patients, it is recommended that with vitamin $\mathrm{D}$ supplementation, plasma calcium and phosphate should be monitored and supplementation dose should be adjusted when required [84] (Fig. 3).

The US NKF developed the Kidney Disease Outcomes Quality Initiative (KDOQI), a specific CKD-MBD guideline (Clinical Practice Guidelines for Bone Metabolism and Disease in Chronic Kidney Disease), published in 2003 [75]. This guideline includes recommendations for the management of vitamin D deficiency and SHPT, calcium and phosphate metabolism. Also the effects of vitamin D deficiency and supplementation on bone metabolism and disease were considered (Table 5). The guideline was predominantly based on evidence on the prevention and management of vitamin D deficiency and the progressive increase of PTH. It is acknowledged that there is a lack of high quality evidence for bone health or patient orientated clinical outcomes, such as mortality and cardiovascular disease risk. Part of this guidance was revised by NKF in 2016 [84] focusing on vitamin D deficiency and SHPT in CKD stages 3-4. In this updated guidance, targets for intact PTH thresholds by CKD category, as defined in the 2003 guideline were removed [84], due to lack of evidence of benefit. Specific 
Table 4 Guidelines for the correction of vitamin D deficiency for patient management (general and for specific groups)

\begin{tabular}{|c|c|c|}
\hline Endocrine society [9] & NICE [67] & ROS [85] \\
\hline \multicolumn{3}{|c|}{ Dosage schemes for the correction of vitamin D deficiency } \\
\hline $\begin{array}{l}\text { Sufficient: }>75 \mathrm{nmol} / \mathrm{L} \\
\text { Insufficient: } 50-75 \mathrm{nmol} / \mathrm{L} \\
\text { Deficiency: }<50 \mathrm{nmol} / \mathrm{L}\end{array}$ & $\begin{array}{l}\text { Sufficient: }>50 \mathrm{nmol} / \mathrm{L} \\
\text { Insufficient: } 25-50 \mathrm{nmol} / \mathrm{L} \\
\text { Deficiency: }<25 \mathrm{nmol} / \mathrm{L}\end{array}$ & $\begin{array}{l}\text { Sufficient: }>50 \mathrm{nmol} / \mathrm{L} \\
\text { Insufficient: } 25-50 \mathrm{nmol} / \mathrm{L} \\
\text { Deficiency: }<25 \mathrm{nmol} / \mathrm{L}\end{array}$ \\
\hline $\begin{array}{l}\text { Dietary intake for patients at risk: 19-70 year } \\
600 \text { IU/day; > 70y } 800 \text { IU/day } \\
\text { Treating vitamin D deficiency in adults: } \\
50,000 \text { IU/week for } 8 \text { weeks or } 6000 \text { IU/day } \\
\text { Followed by maintenance therapy of } 1500- \\
2000 \text { IU/day }\end{array}$ & $\begin{array}{l}\text { Vitamin } \mathrm{D}_{3} \text { is the preferred form of supple- } \\
\text { mentation to treat vitamin D deficiency } \\
\text { Vitamin D deficiency treatment: Fixed loading } \\
\text { dose of vitamin D up to total of } 300,000 \mathrm{IU}, \\
\text { split dose either weekly or daily } \\
\text { Followed by lifelong maintenance treatment of } \\
800 \text { IU/day }\end{array}$ & $\begin{array}{l}\text { Vitamin } \mathrm{D}_{3} \text { is recommended for treating vita- } \\
\text { min } \mathrm{D} \text { deficiency } \\
\text { Vitamin D deficiency treatment: fixed loading } \\
\text { up to a total of } 300,000 \mathrm{IU} \text { given either as } \\
\text { weekly or daily split doses } \\
\text { Maintenance therapy: started one month after } \\
\text { loading with doses equivalent to } 800- \\
2000 \text { IU/day (maximum } 4000 \text { IU/day) given } \\
\text { either daily or intermittently }\end{array}$ \\
\hline
\end{tabular}

No specific guidelines for CKD patients are included. Endocrine society and ROS are led by clinical experts and NICE is a government led committee

dosage schemes for the prevention of vitamin D deficiency for CKD patients are not given in the NKF guidelines 2003 [75] (Table 5), but for the correction of deficiency, recommendations on dosages and duration are provided (Table 6). Vitamin D analogues are recommended only for patients with a progressive increase in PTH and for the treatment of SHPT. The 2016 update highlighted the potential benefits of the use of oral ER 25(OH)D in CKD patients. Few studies were available at that time to support this. In our systematic review, additional studies using this form of vitamin $\mathrm{D}$ are included. In 2017, a commentary was published, reflecting the views of the KDOQI CKD-MBD work group which were mostly in agreement with the updated KDIGO guidelines discussed below [89].

In 2003, the first detailed guidelines by KDIGO was published [1]. In 2017 KDIGO issued their updated guideline for CKD-MBD [90] but little detail on the response to vitamin D supplementation on PTH and bone turnover markers was included. In parallel to the NKF guideline, there are no specific recommendations (type of vitamin $\mathrm{D}$, dose and duration) for the prevention of vitamin D deficiency and the treatment of SHPT due to a lack of sufficient high quality evidence specific to CKD patients. This guideline emphasizes the importance of managing other factors influencing PTH, including a high plasma phosphate and low calcium. This recommendation also considered reported adverse effects (since the previous review) of vitamin D analogues and calcitriol on the development of hypercalcemia, whilst clinically relevant outcomes did not substantially improve. It was therefore concluded that the risk-benefit ratio of treating an elevated PTH with these forms of vitamin D is no longer favourable for the majority of patients [75]. Therefore, in this guideline, the use of vitamin $\mathrm{D}$ analogues and $1,25(\mathrm{OH})_{2} \mathrm{D}$ are recommended only for patients with severe and progressive SHPT (Table 5).
The Kidney Health Australia, CARI guidelines of 2012-2013 [86, 87] and the CKD guidelines for general practice issued in 2015 [88] recommend that vitamin D deficiency in CKD patients should be corrected following guidelines for the general population (Tables 3, 5). Vitamin $\mathrm{D}$ therapy on prescription is recommended for early stages of CKD with SHPT, with regular monitoring of plasma calcium, phosphate, $\mathrm{PTH}$, alkaline phosphatase and 25(OH)D. Treatment with $1,25(\mathrm{OH})_{2} \mathrm{D}$ is only recommended in later stages of CKD for the treatment of SHPT.

\section{Thresholds and Correction of Vitamin D Deficiency}

Thresholds for the definition of vitamin D deficiency for the general population differ between advisory bodies (summarized in Table 3). Some, but not all, also provide thresholds of sufficiency. Recommended 25(OH)D target concentrations and thresholds for deficiency for specific patient groups may be higher than for generally healthy people (Tables 4 , 6). Guidance for the correction of vitamin D deficiency is not provided in population guidance, but instead relies on country-specific clinical guidance for patient management. Tables 4 and 5 provides an overview of the recommendations from 4 authorities, including the NKF $[9,86]$.

There is considerable between-person variation in the dose-response to vitamin $\mathrm{D}$ because of the numerous factors that can affect plasma 25(OH)D and its increment after intake. Reported increases in plasma 25(OH)D in apparently healthy populations (including those that were deficient at baseline) range from 1.1 to $5.75 \mathrm{nmol} / \mathrm{L}$ per $100 \mathrm{IU} /$ day [91-94]. This dose-response relationship is influenced by baseline concentrations of $25(\mathrm{OH}) \mathrm{D}$, vitamin $\mathrm{D}$ dose, frequency of administration, body composition and a number of medical conditions [47]. Population guidance for the prevention of deficiency allows for these variations, but specific 


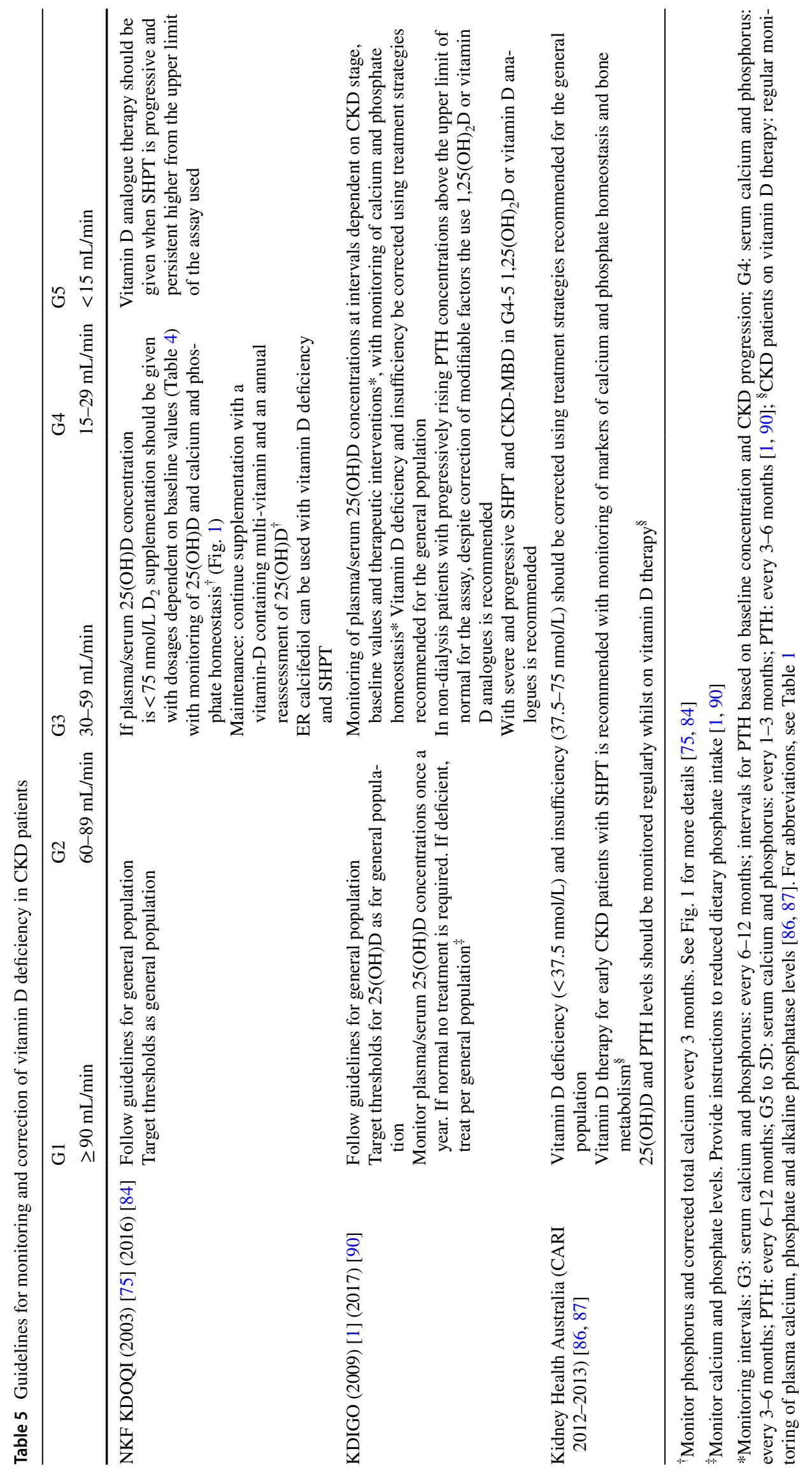


Table 6 Guidelines correction and monitoring of vitamin D deficiency in patients with CKD 3 and 4

\begin{tabular}{|c|c|c|c|c|}
\hline $\begin{array}{l}\text { Serum 25(OH)D nmol/L } \\
{[\mathrm{ng} / \mathrm{mL}]}\end{array}$ & Definition & Vitamin $\mathrm{D}_{2}$ dose & Duration (months) & Comment \\
\hline \multirow[t]{2}{*}{$<12[<5]$} & Severe vitamin D deficiency & $\begin{array}{l}50,000 \mathrm{IU} / \mathrm{w} \text { orally } \times 12 \text { weeks; } \\
\text { then monthly }\end{array}$ & 6 months & $\begin{array}{l}\text { Measure } 25(\mathrm{OH}) \mathrm{D} \text { levels after } \\
6 \text { months }\end{array}$ \\
\hline & & $\begin{array}{l}500,000 \mathrm{IU} \text { as a single I.M. } \\
\text { dose }\end{array}$ & $\mathrm{n} / \mathrm{a}$ & $\begin{array}{l}\text { Assure patient adherence; } \\
\text { measure } 25(\mathrm{OH}) \mathrm{D} \text { at } \\
6 \text { months }\end{array}$ \\
\hline $12-37[5-15]$ & Mild vitamin D deficiency & $\begin{array}{l}50,000 \mathrm{IU} / \mathrm{w} \times 4 \text { weeks; then } 50 \\
000 \mathrm{IU} / \mathrm{m} \text { orally }\end{array}$ & 6 months & $\begin{array}{l}\text { Measure } 25(\mathrm{OH}) \mathrm{D} \text { levels after } \\
6 \text { months }\end{array}$ \\
\hline $40-75[16-29]$ & Vitamin D insufficiency & $50,000 \mathrm{IU} / \mathrm{m}$ orally & 6 months & $\mathrm{n} / \mathrm{a}$ \\
\hline
\end{tabular}

After NKF KDOQI (2003): Guideline 7; Table 26 [75]

at risk groups may need higher intakes to prevent and correct vitamin D deficiency. For the correction of deficiency, higher intakes are required and often loading dosages are recommended, followed by maintenance therapy (Table 4). Clinical monitoring is required with these loading dosages.

Population guidance considered at what concentration range of $25(\mathrm{OH}) \mathrm{D}$, the risk of SHPT was increased and this is incorporated in the assessment of vitamin $\mathrm{D}$ requirements $[8,82]$. Also this relationship is characterized by a large variability and target values for PTH were not formulated for the general population.

In CKD patients, the threshold for vitamin D sufficiency and the vitamin D intake to achieve and maintain sufficiency is less well established than in generally healthy people. This partly due to the fact that few high quality studies relating $25(\mathrm{OH}) \mathrm{D}$ with clinical outcomes, such as fragility fractures or bone mineral density, were conducted in CKD patients. Also, the heterogeneity in this patient group plays a role. In these patients, the vitamin D dose-response and relationship between $25(\mathrm{OH}) \mathrm{D}$ and PTH is dependent of CKD category, renal capacity to produce $1,25(\mathrm{OH})_{2} \mathrm{D}$ and the degree of PTH resistance. Also, diversity in clinical presentation of CKD-MBD, influences the response in bone metabolism.

For CKD patients, a higher target concentration $(>75 \mathrm{nmol} / \mathrm{L})$ than for the general population is recommended in the NKF and CARI guidelines $[84,86]$ with regular monitoring and correction as required on a 6-12 monthly basis (Tables 4, 5, 6 and Fig. 4). Target values for PTH could not be set on the basis of the evidence available. In addition, the PTH-25(OH)D relationship (used formulation of in many population guidelines) could not be used in the assessment of vitamin D requirements for CKD patients due to their altered relationship. Current recommendations advise regular monitoring and management if PTH progressively increases. In view of the variability in clinical presentation, patients are managed on a case-by-case basis with monitoring of calcium and phosphate homeostasis (Fig. 4).

Guidance for management of vitamin D status and deficiency, population recommendations and patient management are summarized in Tables 3, 4 and Fig. 4.

\section{Conclusion}

Major gaps remain in the evidence base for the management of vitamin D status in relation to CKD-MBD, i.e. the dose-response, SHPT, altered bone metabolism, bone density and integrity and fracture risk. Recent studies included in this systematic review varied in design, vitamin D form used there was a high degree of heterogeneity with regard to duration, dose, and population characteristics. Our systematic review showed that the effect of vitamin D on PTH concentrations was inconsistent between studies and metaanalyses showed a non-significant reduction. This is in contrast to findings in studies in patients not selected on basis of pre-existing CKD. This is likely explained by the small sample size of studies and the fact that in some but not all patients with CKD, other drivers are predominant and prevent a decrease of PTH secretion. More consistent effects on PTH was found with calcifediol; all 4 studies that used this form reported a reduced PTH. Also treatment with calcitriol and paricalcitol was associated with a consistent suppression of PTH. An increase Fibroblast Growth Factor 23 (FGF23) after treatment with vitamin $\mathrm{D}$ analogues was observed in all 3 studies reporting this outcome, but was unaltered in 4 studies with Vitamin D or 25(OH)D. The increase in FGF23 with analogue administration warrants attention as this hormone is already elevated in CKD patients and is a predictor of vascular calcification and CVD. It's increase may indicate an undesirable side effect of administration of these forms of vitamin 
Fig. 3 Changes in Vitamin D metabolism and the renal-bone axis with CKD. Arrows indicate direction of changes with CKD. With chronic kidney disease the combination of limited vitamin $D$ intake and reduced renal capacity to activate $25(\mathrm{OH}) \mathrm{D}$ to $1,25(\mathrm{OH})_{2} \mathrm{D}$ results to a chain reaction of changes in metabolism. A decrease in $1,25(\mathrm{OH})_{2} \mathrm{D}$ results in a decrease in intestinal absorption of calcium. This stimulates PTH secretion which in turn increases bone resorption. Phosphate retention due to reduced kidney filtration capacity further stimulates PTH and the production and release of FGF23 from bone cells to increase renal phosphate excretion

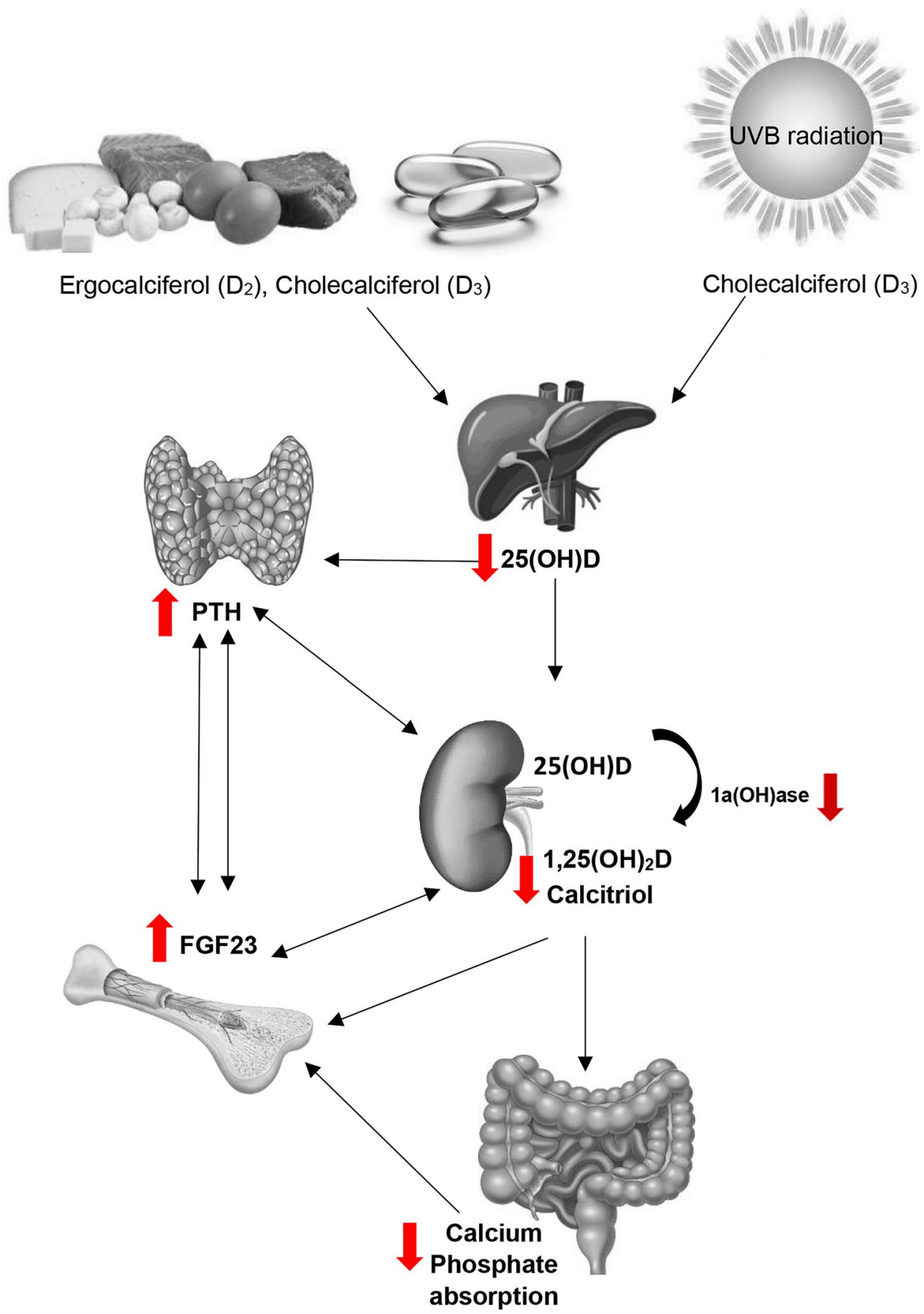

D. Few RCTs reported the effect of vitamin D on markers of bone metabolism and variations in the range of markers prevented direct comparisons. However, all 4 studies that measured either ALP or BALP after paricalcitol treatment reported a decrease in this marker that is indicative of increased bone turnover in CKD patients.
Guidelines for the first stages (G1-G3a) follow general population recommendations for the prevention of vitamin $\mathrm{D}$ deficiency. For the correction of deficiency, general or CKD specific patient guidelines provide recommendations. These are summarized in a tabulated format to facilitate their use in clinical practice. 


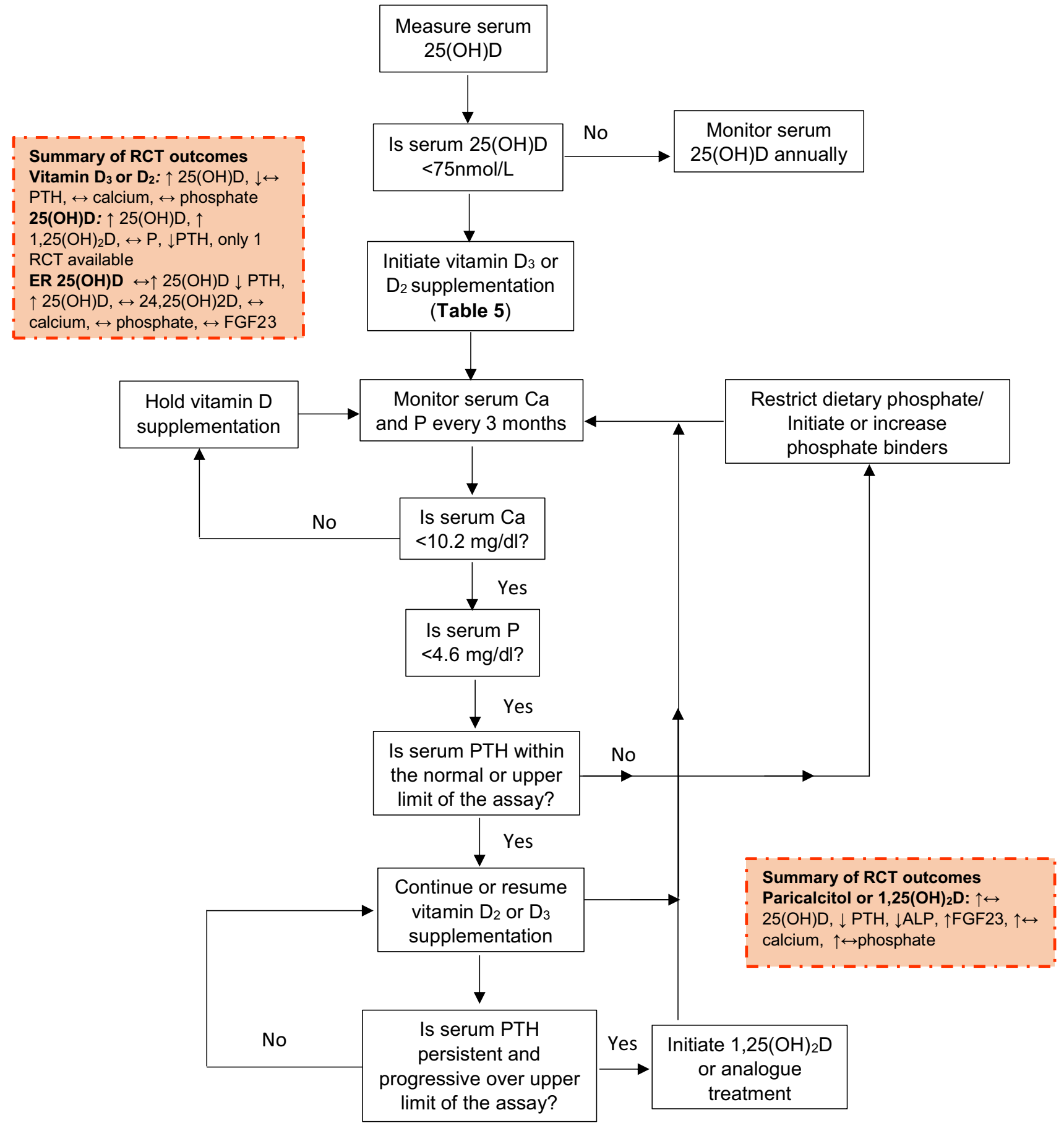

Fig. 4 Guidance for monitoring of vitamin D status and supplementation and monitoring of calcium and phosphate metabolism in CKD stages G3-4. Based on recommendations from the different organizations summarized in Table 5. Adapted from: NKF KDOQI (2003)
[75]. Finding in recent RCTs (2003-2020) included in the systematic review are summarized in yellow boxes. For abbreviations see Table 1 
Acknowledgements This study was funded by Academy of Medical Sciences and the University of East Anglia, UK. We are grateful to Dr Antony Fulford for his advice on statistical analyses and interpretation.

Author Contributions MC (study design, data analysis, paper writing, commenting on the final version of the paper), TJA (study design, paper writing, commenting on the final version of the paper), IS (study design, data analysis, paper writing, commenting on the final version of the paper).

Funding This study was supported by the Academy of Medical Sciences and Wellcome Trust [SBF002\1097] and the University of East Anglia, UK.

Data Availability All data are publicly available.

\section{Declarations}

Conflict of interest Authors Marilena Christodoulou, Terence J. Aspray and Inez Schoenmakers declare that they have no conflict of interest to disclose.

Human and Animal Rights Not applicable.

Informed Consent Not applicable.

Open Access This article is licensed under a Creative Commons Attribution 4.0 International License, which permits use, sharing, adaptation, distribution and reproduction in any medium or format, as long as you give appropriate credit to the original author(s) and the source, provide a link to the Creative Commons licence, and indicate if changes were made. The images or other third party material in this article are included in the article's Creative Commons licence, unless indicated otherwise in a credit line to the material. If material is not included in the article's Creative Commons licence and your intended use is not permitted by statutory regulation or exceeds the permitted use, you will need to obtain permission directly from the copyright holder. To view a copy of this licence, visit http://creativecommons.org/licenses/by/4.0/.

\section{References}

1. Group KDIGO (KDIGO) C-MW (2009) KDIGO clinical practice guideline for the diagnosis, evaluation, prevention, and treatment of Chronic Kidney Disease-Mineral and Bone Disorder (CKDMBD). Kidney Int Suppl. https://doi.org/10.1038/ki.2009.188

2. Schaeffner ES, Ebert N, Delanaye P et al (2012) Two novel equations to estimate kidney function in persons aged 70 years or older. Ann Intern Med 157:471. https://doi.org/10.7326/0003-4819-1577-201210020-00003

3. Coresh J, Selvin E, Stevens LA et al (2007) Prevalence of chronic kidney disease in the United States. JAMA 298:2038. https://doi. org/10.1001/jama.298.17.2038

4. Stevens PE, Levin A, Kidney Disease: Improving Global Outcomes Chronic Kidney Disease Guideline Development Work Group Members (2013) Evaluation and management of chronic kidney disease: synopsis of the kidney disease: improving global outcomes 2012 clinical practice guideline. Ann Intern Med 158:825. https://doi.org/10.7326/0003-4819-158-11-20130 6040-00007

5. Kerr M (2012) Chronic kidney disease in England: the human and financial cost
6. Nigwekar SU, Bhan I, Thadhani R (2012) Ergocalciferol and cholecalciferol in CKD. Am J Kidney Dis 60:139-156. https:// doi.org/10.1053/j.ajkd.2011.12.035

7. Moe SM (2010) Definition and classification of renal osteodystrophy and chronic kidney disease-mineral bone disorder (CKDMBD). In: The spectrum of mineral and bone disorders in chronic kidney disease. Oxford University Press, pp 1-14

8. SACN (2016) Vitamin D and health 2016

9. Holick MF, Binkley NC, Bischoff-Ferrari HA et al (2011) Evaluation, treatment, and prevention of vitamin D deficiency: an endocrine society clinical practice guideline. J Clin Endocrinol Metab 96:1911-1930

10. Rhee CM, Ahmadi S-F, Kovesdy CP, Kalantar-Zadeh K (2018) Low-protein diet for conservative management of chronic kidney disease: a systematic review and meta-analysis of controlled trials. J Cachexia Sarcopenia Muscle 9:235-245. https://doi.org/10. 1002/jcsm. 12264

11. Christakos S, Ajibade DV, Dhawan P et al (2010) Vitamin D: metabolism. Endocrinol Metab Clin N Am 39:243-53. https:// doi.org/10.1016/j.ecl.2010.02.002

12. Michaud J, Naud J, Ouimet D et al (2010) Reduced hepatic synthesis of calcidiol in uremia. J Am Soc Nephrol 21:1488-1497. https://doi.org/10.1681/ASN.2009080815

13. Prosser D, Jones G (2004) Enzymes involved in the activation and inactivation of vitamin D. Trends Biochem Sci 29:664-673. https://doi.org/10.1016/j.tibs.2004.10.005

14. Anderson PH, Lam NN, Turner AG et al (2013) The pleiotropic effects of vitamin D in bone. J Steroid Biochem Mol Biol 136:190-194

15. Evenepoel P, Bover J, Ureña Torres P (2016) Parathyroid hormone metabolism and signaling in health and chronic kidney disease. Kidney Int 90:1184-1190. https://doi.org/10.1016/J.KINT.2016. 06.041

16. Isakova T, Wahl P, Vargas GS et al (2011) Fibroblast growth factor 23 is elevated before parathyroid hormone and phosphate in chronic kidney disease. Kidney Int 79:1370-1378. https://doi.org/ 10.1038/KI.2011.47

17. De Francisco ALM (2004) Secondary hyperparathyroidism: review of the disease and its treatment. Clin Ther 26:1976-1993. https://doi.org/10.1016/j.clinthera.2004.12.011

18. Alvarez JA, Zughaier SM, Law J et al (2013) Effects of high-dose cholecalciferol on serum markers of inflammation and immunity in patients with early chronic kidney disease. Eur J Clin Nutr 67:264-269. https://doi.org/10.1038/ejcn.2012.217

19. Lundwall K, Jörneskog G, Jacobson SH, Spaak J (2015) Paricalcitol, microvascular and endothelial function in non-diabetic chronic kidney disease: a randomized trial. Am J Nephrol 42:265-273. https://doi.org/10.1159/000441364

20. Levin A, Perry T, De Zoysa P et al (2014) A randomized control trial to assess the impact of vitamin D supplementation compared to placebo on vascular stiffness in chronic kidney disease patients. BMC Cardiovasc Disord. https://doi.org/10. 1186/1471-2261-14-156

21. Susantitaphong P, Nakwan S, Peerapornratana S et al (2017) A double-blind, randomized, placebo-controlled trial of combined calcitriol and ergocalciferol versus ergocalciferol alone in chronic kidney disease with proteinuria. BMC Nephrol. https:// doi.org/10.1186/s12882-017-0436-6

22. Sprague SM, Silva AL, Al-Saghir F et al (2014) Modifiedrelease calcifediol effectively controls secondary hyperparathyroidism associated with vitamin D insufficiency in chronic kidney disease. Am J Nephrol 40:535-545. https://doi.org/10. 1159/000369939

23. Cupisti A, Egidi MF, Vigo V et al (2015) Vitamin D status and cholecalciferol supplementation in chronic kidney disease 
patients: an Italian cohort report. Int J Nephrol Renovasc Dis 8:151. https://doi.org/10.2147/IJNRD.S90968

24. Alvarez JA, Law J, Coakley KE et al (2012) High-dose cholecalciferol reduces parathyroid hormone in patients with early chronic kidney disease: a pilot, randomized, double-blind, placebo-controlled trial. Am J Clin Nutr 96:672-679. https://doi.org/10.3945/ ajcn.112.040642

25. Petchey WG, Hickman IJ, Prins JB et al (2013) Vitamin D does not improve the metabolic health of patients with chronic kidney disease stage 3-4: a randomized controlled trial. Nephrology 18:26-35. https://doi.org/10.1111/j.1440-1797.2012.01662.x

26. de Boer IH, Sachs M, Hoofnagle AN et al (2013) Paricalcitol does not improve glucose metabolism in patients with stage 3-4 chronic kidney disease. Kidney Int 83:323-330. https://doi.org/ 10.1038/ki.2012.311

27. Alborzi P, Patel NA, Peterson C et al (2008) Paricalcitol reduces albuminuria and inflammation in chronic kidney disease a randomized double-blind pilot trial. Hypertension 52:249-255. https:// doi.org/10.1161/HYPERTENSIONAHA.108.113159

28. Larsen T, Mose FH, Bech JN, Pedersen EB (2013) Effect of paricalcitol on renin and albuminuria in non-diabetic stage III-IV chronic kidney disease: a randomized placebo-controlled trial. BMC Nephrol. https://doi.org/10.1186/1471-2369-14-163

29. Dreyer G, Tucker AT, Harwood SM et al (2014) Ergocalciferol and microcirculatory function in chronic kidney disease and concomitant vitamin D deficiency: an exploratory, double blind, randomised controlled trial. PLoS ONE. https://doi.org/10.1371/ journal.pone.0099461

30. Thadhani R, Appelbaum E, Pritchett $Y$ et al (2012) Vitamin D therapy and cardiac structure and function in patients with chronic kidney disease: the PRIMO randomized controlled trial. JAMA 307:674-684. https://doi.org/10.1001/jama.2012.120

31. Yadav AK, Kumar V, Banerjee D et al (2018) Effect of vitamin D supplementation on serum sclerostin levels in chronic kidney disease 180:15-18. https://doi.org/10.1016/j.jsbmb.2018.01.007

32. Kim MJ, Frankel AH, Donaldson M et al (2011) Oral cholecalciferol decreases albuminuria and urinary TGF- $\beta 1$ in patients with type 2 diabetic nephropathy on established renin-angiotensinaldosterone system inhibition. Kidney Int 80:851-860. https://doi. org/10.1038/ki.2011.224

33. Aytaç MB, Deveci M, Bek K et al (2016) Effect of cholecalciferol on local arterial stiffness and endothelial dysfunction in children with chronic kidney disease. Pediatr Nephrol 31:267-277. https:// doi.org/10.1007/s00467-015-3220-5

34. Meireles MS, Kamimura MA, Dalboni MA et al (2016) Effect of cholecalciferol on vitamin D-regulatory proteins in monocytes and on inflammatory markers in dialysis patients: a randomized controlled trial. Clin Nutr 35:1251-1258. https://doi.org/10.1016/j. clnu.2016.04.014

35. Zisman AL, Hristova M, Ho LT, Sprague SM (2007) Impact of ergocalciferol treatment of vitamin D deficiency on serum parathyroid hormone concentrations in chronic kidney disease. Am J Nephrol 27:36-43. https://doi.org/10.1159/000098561

36. Al-Aly Z, Qazi RA, González EA et al (2007) Changes in serum 25-hydroxyvitamin D and plasma intact PTH levels following treatment with ergocalciferol in patients with CKD. Am J Kidney Dis 50:59-68. https://doi.org/10.1053/J.AJKD.2007.04.010

37. Slatopolsky E, Weerts C, Thielan J et al (1984) Marked suppression of secondary hyperparathyroidism by intravenous administration of 1,25-dihydroxy-cholecalciferol in uremic patients. J Clin Invest 74:2136-2143. https://doi.org/10.1172/JCI111639

38. Berl T, Berns AS, Hufer WE et al (1978) 1,25 dihydroxycholecalciferol effects in chronic dialysis. A double-blind controlled study. Ann Intern Med 88:774-780. https://doi.org/10.7326/ 0003-4819-88-6-774
39. Koizumi M, Komaba H, Fukagawa M (2013) Parathyroid function in chronic kidney disease: role of FGF23-Klotho axis. Contrib Nephrol 180:110-123. https://doi.org/10.1159/000346791

40. van Tulder M, Furlan A, Bombardier C et al (2003) Updated method guidelines for systematic reviews in the cochrane collaboration back review group. Spine 28:1290-9. https://doi.org/ 10.1097/01.BRS.0000065484.95996.AF

41. Dogan E, Erkoc R, Sayarlioglu H et al (2008) Effect of depot oral cholecalciferol treatment on secondary hyperparathyroidism in stage 3 and stage 4 chronic kidney diseases patients. Ren Fail 30:407-410. https://doi.org/10.1080/08860220801964210

42. Okša A, Spustová V, Krivošíková Z et al (2008) Effects of longterm cholecalciferol supplementation on mineral metabolism and calciotropic hormones in chronic kidney disease. Kidney Blood Press Res 31:322-329. https://doi.org/10.1159/000157177

43. Moe SM, Saifullah A, LaClair RE et al (2010) A randomized trial of cholecalciferol versus doxercalciferol for lowering parathyroid hormone in chronic kidney disease. Clin J Am Soc Nephrol 5:299-306. https://doi.org/10.2215/CJN.07131009

44. Chandra P, Binongo JNG, Ziegler TR et al (2008) Cholecalciferol (vitamin D3) therapy and vitamin D insufficiency in patients with chronic kidney disease: a randomized controlled pilot study. Endocr Pract 14:10-17. https://doi.org/10.4158/EP.14.1.10

45. Westerberg A, Sterner G, Ljunggren O et al (2018) High doses of cholecalciferol alleviate the progression of hyperparathyroidism in patients with CKD Stages 3-4: results of a 12-week double-blind, randomized, controlled study. Nephrol Dial Transpl 33:466-471. https://doi.org/10.1093/ndt/gfx059

46. Kovesdy CP, Lu JL, Malakauskas SM et al (2012) Paricalcitol versus ergocalciferol for secondary hyperparathyroidism in CKD stages 3 and 4: a randomized controlled trial. Am J Kidney Dis 59:58-66. https://doi.org/10.1053/j.ajkd.2011.06.027

47. Petkovich M. BCW (2018) Vitamin D: Volume 1: Biochemistry, Physiology and Diagnostics. In: David F, Wesley PJ, Roger B, Edward G, David HMG (eds), 4th edn. Elsevier, pp 667-678

48. Petkovich M, Melnick J, White J et al (2015) Modified-release oral calcifediol corrects vitamin D insufficiency with minimal CYP24A1 upregulation. J Steroid Biochem Mol Biol 148:283289. https://doi.org/10.1016/j.jsbmb.2014.11.022

49. Sprague SM, Crawford PW, Melnick JZ et al (2016) Use of extended-release calcifediol to treat secondary hyperparathyroidism in stages 3 and 4 chronic kidney disease. Am J Nephrol 44:316-325. https://doi.org/10.1159/000450766

50. Levin A, Tang M, Perry T et al (2017) Randomized controlled trial for the effect of vitamin D supplementation on vascular stiffness in CKD. Clin J Am Soc Nephrol 12:1447-1460. https://doi. org/10.2215/CJN.10791016

51. Evenepoel P (2008) Calcimimetics in chronic kidney disease: evidence, opportunities and challenges. Kidney Int 74:265-275. https://doi.org/10.1038/ki.2008.166

52. Slatopolsky E, Weerts C, Thielan J et al (1984) Marked suppression of secondary hyperparathyroidism by intravenous administration of 1,25-dihydroxycholecalciferol in uremic patients. J Clin Invest 74:2136-2143. https://doi.org/10.1172/JCI111639

53. De Zeeuw D, Agarwal R, Amdahl M et al (2010) Selective vitamin $\mathrm{D}$ receptor activation with paricalcitol for reduction of albuminuria in patients with type 2 diabetes (VITAL study): a randomised controlled trial. Lancet 376:1543-1551. https://doi. org/10.1016/S0140-6736(10)61032-X

54. Wang AYM, Fang F, Chan J et al (2014) Effect of paricalcitol on left ventricular mass and function in CKD-The OPERA trial. J Am Soc Nephrol 25:175-186. https://doi.org/10.1681/ASN.20130 10103

55. Zoccali C, Curatola G, Panuccio V et al (2014) Paricalcitol and endothelial function in chronic kidney disease trial. Hypertension 
64:1005-1011. https://doi.org/10.1161/HYPERTENSIONAHA. 114.03748

56. Riccio E, Sabbatini M, Bruzzese D et al (2015) Effect of paricalcitol vs calcitriol on hemoglobin levels in chronic kidney disease patients: a randomized trial. PLoS ONE. https://doi.org/10.1371/ journal.pone.0118174

57. Coyne D, Acharya M, Qiu P et al (2006) Paricalcitol capsule for the treatment of secondary hyperparathyroidism in stages 3 and 4 CKD. Am J Kidney Dis 47:263-276. https://doi.org/10.1053/j. ajkd.2005.10.007

58. Coyne DW, Goldberg S, Faber M et al (2014) A randomized multicenter trial of paricalcitol versus calcitriol for secondary hyperparathyroidism in stages 3-4 CKD. Clin J Am Soc Nephrol 9:1620-1626. https://doi.org/10.2215/CJN.10661013

59. Moslehi N, Shab-Bidar S, Mirmiran P et al (2013) Determinants of parathyroid hormone response to Vitamin D supplementation: a systematic review and meta-analysis of randomised controlled trials. Br J Nutr 114:1360-1374. https://doi.org/10.1017/S0007 114515003189

60. Cranney A, Horsley T, O'Donnell S, et al (2007) Effectiveness and safety of vitamin D in relation to bone health. Agency for Healthcare Research and Quality (US)

61. Shimada T, Hasegawa H, Yamazaki Y et al (2003) FGF-23 is a potent regulator of vitamin D metabolism and phosphate homeostasis. J Bone Miner Res 19:429-435. https://doi.org/10.1359/ JBMR.0301264

62. Middleton R, Parfrey P, Foley R et al (2014) Left ventricular hypertrophy in the renal patient. J Am Soc Nephrol 12:10791084. https://doi.org/10.1681/asn.2013050465

63. Lattanzio MR, Weir MR (2010) Does blockade of the reninangiotensin-aldosterone system slow progression of all forms of kidney disease? Curr Hypertens Rep 12:369-377. https://doi.org/ 10.1007/s11906-010-0142-2

64. Charoenngam N, Rujirachun P, Holick MF, Ungprasert P (2019) Oral vitamin D3 supplementation increases serum fibroblast growth factor 23 concentration in vitamin D-deficient patients: a systematic review and meta-analysis. Osteoporos Int 30:2183-2193

65. Hojs R, Bevc S, Ekart R et al (2008) Serum crystatin C-based equation compared to serum creatinine-based equations for estimation of glomerular filtration rate in patient with chronic kidney disease. Clin Nephrol 70:10-17. https://doi.org/10.5414/cnp70010

66. National Kidney Foundation (2009) Cystatin C

67. NICE (2019) Chronic kidney disease - NICE CKS. https://cks.nice. org.uk/chronic-kidney-disease\#!scenario. Accessed 4 Dec 2019

68. National Institute for Clinical Excellence (2015) Chronic kidney disease in adults: assessment and management. NICE

69. Pedone C, Corsonello A, Incalzi RA (2006) Estimating renal function in older people: a comparison of three formulas. Age Ageing 35:121-126. https://doi.org/10.1093/ageing/afj041

70. Yuste C, Quiroga B, García de Vinuesa S et al (2015) The effect of some medications given to CKD patients on vitamin D levels. Nefrol 35:150-156. https://doi.org/10.1016/J.NEFROE.2015.05. 006

71. Manson JE, Bassuk SS, Lee I-M et al (2012) The VITamin D and OmegA-3 TriaL (VITAL): rationale and design of a large randomized controlled trial of vitamin $\mathrm{D}$ and marine omega-3 fatty acid supplements for the primary prevention of cancer and cardiovascular disease. Contemp Clin Trials 33:159-171. https:// doi.org/10.1016/j.cct.2011.09.009

72. Dusso AS (2011) Kidney disease and vitamin D levels: 25-hydroxyvitamin D, 1,25-dihydroxyvitamin D, and VDR activation. Kidney Int Suppl 1:136-141. https://doi.org/10.1038/kisup.2011.30

73. Caravaca-Fontán F, Gonzales-Candia B, Luna E, Caravaca F (2016) Relative importance of the determinants of serum levels of 25-hydroxy vitamin $\mathrm{D}$ in patients with chronic kidney disease. Nefrol 36:510-516. https://doi.org/10.1016/j.nefroe.2016.11.010

74. Chan S, Au K, Francis RS et al (2017) Phosphate binders in patients with chronic kidney disease. Aust Prescr 40:9-14

75. National Kidney Foundation (2003) K/DOQI clinical practice guidelines for bone metabolism and disease in chronic kidney disease. Am J Kidney Dis 42:1-202

76. Feldman D (2018) Vitamin D, vol 2. Academic Press, Health, Disease and Therapeutics

77. Ginsberg C, Zelnick LR, Block GA et al (2020) Differential effects of phosphate binders on vitamin D metabolism in chronic kidney disease. Nephrol Dial Transpl 35:616-623. https://doi.org/10. 1093/ndt/gfaa010

78. Bouillon R (2017) Comparative analysis of nutritional guidelines for vitamin D. Nat Rev Endocrinol 13:466-479

79. Lips P, Cashman KD, Lamberg-Allardt C, Bischoff-Ferrari HA, Obermayer-Pietsch B, Bianchi ML, Stepan J et al (2019) Current vitamin D status in European and Middle East countries and strategies to prevent vitamin D deficiency: a position statement of the European Calcified Tissue Society. Eur J Endocrinol 180:23-54. https://doi.org/10.1530/EJE-18-0736

80. Ross AC, Manson JAE, Abrams SA et al (2011) The 2011 report on dietary reference intakes for calcium and vitamin $D$ from the Institute of Medicine: what clinicians need to know. J Clin Endocrinol Metab 96:53-58

81. European Food Safety Authority (EFSA) (2017) Technical Report dietary reference values for nutrients summary report. https://doi. org/10.2903/sp.efsa.2017.e15121

82. IOM (Institute of Medicine) (2011) Dietary reference intakes for calcium and vitamin D

83. Vitamin D deficiency in adults - treatment and prevention - NICE CKS. https://cks.nice.org.uk/vitamin-d-deficiency-in-adults-treat ment-and-prevention\#!scenario. Accessed 4 Dec 2019

84. National Kidney Foundation (2016) A clinical update on vitamin $\mathrm{D}$ deficiency and secondary hyperparathyroidism: vitamin D testing and supplementation in CKD stages 3-4 part 2

85. Francis R, Aspray T, Fraser W, Macdonald H, Patel S, Mavroeidi A, Schoenmakers I (2018) Vitamin D and bone health: a practical clinical guideline for patient management. R Osteoporos Soc 1-25

86. Chan M, Johnson D (2012) Vitamin D therapy (supplementation) in early chronic kidney disease

87. Johnson DW, Atai E, Chan M et al (2013) KHA-CARI guideline: early chronic kidney disease: detection, prevention and management. Nephrology 18:340-350. https://doi.org/10.1111/nep.12052

88. Kidney Health Australia (2015) Chronic kidney disease (CKD) management in general practice, 4 th ed. Melbourne

89. Isakova T, Nickolas TL, Denburg M et al (2017) KDOQI US commentary on the 2017 KDIGO clinical practice guideline update for the diagnosis, evaluation, prevention, and treatment of chronic kidney disease-mineral and bone disorder (CKD-MBD). Am J Kidney Dis 70:737-751. https://doi.org/10.1053/j.ajkd.2017.07. 019

90. KDIGO (2017) KDIGO 2017 clinical practice guideline update for the diagnosis, evaluation, prevention, and treatment of chronic kidney disease-mineral and bone disorder (CKD-MBD). Kidney Int Suppl 7:1-59. https://doi.org/10.1016/j.kisu.2017.04.001

91. Autier P, Gandini S, Mullie P (2012) A systematic review: Influence of vitamin D supplementation on serum 25-hydroxyvitamin D concentration. J Clin Endocrinol Metab 97:2606-2613

92. Heaney RP, Armas LA, Shary JR, et al (2008) 25-Hydroxylation of vitamin D 3: relation to circulating vitamin D 3 under various input conditions 1-3

93. Singh G, Bonham AJ (2014) A predictive equation to guide vitamin D replacement dose in patients. J Am Board Fam Med 27:495-509. https://doi.org/10.3122/jabfm.2014.04.130306 
94. Cashman KD, Fitzgerald AP, Kiely M, Seamans KM (2011) A systematic review and meta-regression analysis of the vitamin $\mathrm{D}$ intake-serum 25-hydroxyvitamin D relationship to inform European recommendations. Br J Nutr 106:1638-1648

95. Hoteit M, Al-Shaar L, Yazbeck C et al (2014) Hypovitaminosis D in a sunny country: time trends, predictors, and implications for practice guidelines. Metabolism 63:968-978. https://doi.org/10. 1016/j.metabol.2014.04.009

96. SCAN (2016) Vitamin D and health 2016

97. Food Safety Authority of Ireland (1999) Recommended dietary allowances for Ireland: 1999
98. Spiro A, Buttriss JL (2014) Vitamin D: an overview of vitamin D status and intake in Europe. Nutr Bull 39:322-350. https://doi. org/10.1111/nbu. 12108

Publisher's Note Springer Nature remains neutral with regard to jurisdictional claims in published maps and institutional affiliations. 